\title{
Bischöfe, Humanisten und einfache Lutherfeinde. Die Kontakte des Erasmus nach Polen im Spiegel seines Briefwechsels
}

W jaki sposób reformacja w Niemczech krytykowana była przez intelektualne, świeckie i duchowne elity Królestwa Polskiego? Jakie można tu wyróżnić stanowiska, uwzględniając ich zmienność w czasie? Czy w Polsce byli zwolennicy, a może wręcz patroni idei reformacyjnych? W poszukiwaniu odpowiedzi na te pytania sięgnięto po korespondencję Erazma z Rotterdamu, ponieważ utrzymywał on kontakty z wieloma Polakami i osobami w Polsce żyjącymi, a ponadto stanowił dla nich najważniejsze źródło informacji o rozwoju sytuacji w Niemczech.

How has the reformation in Germany been criticized by the intellectual, secular, and ecclesiastical elite of the Polish kingdom? Which different positions are to be made, even in their temporal development? Have there been followers or even patrons of the reformatory ideas in Poland at all? To give answers to these questions, the correspondence of Erasmus of Rotterdam has been chosen, as he not only stayed in contact with numerous Polish or in Poland living people, but he also acts for them as the most important person to give information about the development in Germany.

Słow a kluczowe: Erazm z Rotterdamu, korespondencja, intelektualne, świeckie i duchowne elity Polski, Marcin Luter, reformacja

Ke yw o rds: Erasmus of Rotterdam, correspondence, intellectual, secular, and ecclesiastical elite of Poland, Martin Luther, Reformation 
Briefe gehören unter die wichtigsten Denkmäler, die der einzelne Mensch hinterlassen kann. Lebhafte Personen stellen sich schon bei ihren Selbstgesprächen manchmal einen abwesenden Freund als gegenwärtig vor, dem sie ihre innersten Gesinnungen mittheilen, und so ist auch der Brief eine Art von Selbstgespräch. ${ }^{1}$

Diese Aussage, die Goethe Winckelmann in den Mund legte, verweist auf den Quellenwert überlieferter Briefe und erklärt die Hinwendung der jüngeren Forschung auf die als Ego-Dokumente bezeichneten Zeugnisse. ${ }^{2}$ Darunter können ,jene Quellen verstanden werden, in denen ein Mensch Auskunft über sich selbst gibt, unabhängig davon, ob dies freiwillig [- - ] oder durch andere Umstände bedingt" ${ }^{3}$ Dass weiterhin diskutiert wird, ob der Brief als historische Quelle von Akten und Urkunden zu unterscheiden ist, ${ }^{4}$ erklärt sich aus der Vielfalt seiner Erscheinungsformen in unterschiedlichen Zeiten. In diesem Zusammenhang ist vor allem auch zu beachten, ob es sich um einen Privatbrief oder einen für die Öffentlichkeit bestimmten Brief handelt. Auch die bereits in der Abfassung berücksichtigte Möglichkeit einer Veröffentlichung durch den Empfänger muss mitgedacht werden. In all diesen Fällen wird der Verfasser üblicherweise vorab überlegt haben, auf welche Weise er welche Informationen mitteilen und preisgeben will. Die historische Interpretation hat daher bei der inhaltlichen Auswertung stets Entstehungsumstände, Motive und Intentionen zu berücksichtigen. Davon abgesehen sind in aller Regel grundlegende Informationen zu gewinnen: Bereits ein einzelner Brief, noch mehr aber eine überlieferte Korrespondenz kann

${ }^{1}$ H. Böhlau, Goethes Werke. I. Abtheilung, Bd. 46 (Weimar, 1891), S. 11-12.

${ }^{2} \mathrm{Vgl}$. dazu u.a. W. Schulze, „Ego-Dokumente: Annäherung an den Menschen in der Geschichte?", in: Von Aufbruch und Utopie, hrsg. v. B. Lundt, H. Reimöller (Köln, Weimar und Wien, 1992), S. 417-450; B. von Krusenstjern, „Was sind Selbstzeugnisse? Begriffskritische und quellenkundliche Überlegungen anhand von Beispielen aus dem 17. Jahrhundert", Historische Anthropologie 2 (1994), S. 462-471; K. von Greyerz, „Ego-Documents: The Last Word?“, German History 28, Nr. 3 (2010), S. 273-282; M. Fulbrook, U. Rublack, „In Relation: The ,Social Self and Ego-Documents“, German History 28, Nr. 3 (2010), S. 263-272; J. Peters, „Wegweiser zum Innenleben? Möglichkeiten und Grenzen der Untersuchung populärer Selbstzeugnisse der Frühen Neuzeit“, Historische Anthropologie 1 (1993), S. 235-249; C. Furger, Briefsteller. Das Medium ,Brief im 17. und frühen 18. Jahrhundert (Köln, Weimar und Wien, 2010).

3 Schulze, op. cit., S. 482-483.

${ }^{4} \mathrm{Vgl}$. dazu I. Schmid, „Was ist ein Brief? Zur Begriffsbestimmung des Terminus ,Brief" als Bezeichnung einer quellenkundlichen Gattung", Editio 2 (1988), S. 1-7, hier: S. 2, Anm. 6, sowie S. 4-5. 
Aufschluss darüber geben, mit wem eine Person in Kontakt stand. Dabei lassen die Empfänger ihrer Briefe, vor allem aber die Adressaten der an sie adressierten Schreiben Rückschlüsse auf ihr Netzwerk und ihre gesellschaftliche Stellung sowie ihr Ansehen unter und ihre Bedeutung für die Zeitgenossen zu. ${ }^{5}$ Ferner können Informationen über die Lebenssituation der Briefpartner gewonnen werden - unter Umständen auch, was sie beschäftigt und bewegt hat.

Für die Humanisten des 15. und 16. Jahrhunderts stellte der Brief das zentrale Kommunikationsmedium dar. ${ }^{6}$ Franz Josef Worstbrock hat daher zu Recht von der „literarischen Schlüsselform der Epoche“7 gesprochen. Damit war es möglich, über Landesgrenzen hinweg mit der ,res publica litteraria' in Verbindung zu bleiben. Den Privatbrief im heutigen Sinne gab es zu dieser Zeit kaum. Etwa durch das für die Zeit übliche öffentliche Vorlesen gelangte ein Brief bereits an die Öffentlichkeit - oder besser: eine Teilöffentlichkeit, ohne dass er erst publiziert werden musste. ${ }^{8}$ Diese Umstände veranlassten den Briefschreiber, entsprechend zu formulieren, auf Themen einzugehen oder auch manche Aspekte auszuklammern. Eingedenk dieser Abfassungsumstände erfährt man jedoch meist umso mehr über die tatsächlich behandelten Themen und deren zeitgenössische Wahrnehmung.

${ }^{5}$ Vgl. C. Treml, Humanistische Gemeinschaftsbildung. Sozio-kulturelle Untersuchung zur Entstehung eines neuen Gelehrtenstandes in der frühen Neuzeit (Hildesheim, Zürich und New York, 1989), S. 86: „Die Einschätzung der eigenen Person durch den Gelehrtenzirkel bemaß sich auch an der Anzahl und der Bedeutung der Freunde, auf die man verweisen konnte."

${ }^{6}$ Vgl. ibidem, S. 16: „Der besonderen Struktur der humanistischen Kommunikation ist es zu verdanken, daß mit den Korrespondenten eines Zirkels sowohl die engeren als auch die sympathisierenden Mitglieder erfaßt sind, da der briefliche Kontakt zu möglichst vielen und möglichst bedeutenden Gelehrten für die Humanisten eine conditio sine qua non ihrer Zugehörigkeit zur respublica literaria darstellte."

${ }^{7}$ F. J. Worstbrock, „Vorwort“, in: Der Brief im Zeitalter der Renaissance, hrsg. v. F. J. Worstbrock (Weinheim, 1983), S. 5-6, hier: S. 5.

${ }^{8}$ Vgl. P. Bürgel, „Der Privatbrief. Entwurf eines heuristischen Modells“, Deutsche Vierteljahrsschrift für Literaturwissenschaft und Geistesgeschichte 50, Nr. 1 (1976), S. 281-297; M. Arnold, „Die Rolle der Korrespondenz bei Kommunikation und Transfer. Zu einer evangelischen Identität in der Frühen Neuzeit“, in: Kommunikation und Transfer im Christentum der Frühen Neuzeit, hrsg. v. I. Dingel, W.-F. Schäufele (Mainz, 2007), S. 33-47, hier: S. 35: „Allerdings war ein Privatbrief im 16. Jahrhundert nicht so vertraulich wie dies heutzutage der Fall ist. Die Mehrzahl der Briefe Luthers sind uns in Abschriften überliefert worden, die bereits von seinen Zeitgenossen angefertigt wurden." 
Vor diesem Hintergrund stellen Briefe wohl die wertvollste historische Quelle dar, um im Folgenden der Frage nachzugehen, mit welchen polnischen oder in Polen lebenden Zeitgenossen der Humanistenfürst Erasmus von Rotterdam ${ }^{9}$ in Kontakt stand. Mit Blick auf den Inhalt der untereinander gewechselten Briefe soll es vor allem um die Frage gehen, welche Rolle die reformatorische Bewegung im Reich sowie die Person Martin Luthers spielten. Dabei soll nicht so sehr die Haltung des Erasmus im Vordergrund stehen als vielmehr die Wahrnehmung und die Haltung seiner polnischen Briefpartner. Die Korrespondenz des Erasmus bietet sich für diesen Zweck aus mindestens zwei Gründen an: So hat er selbst bereits früh begonnen, Briefe zu archivieren und in Auswahl gelegentlich zu publizieren. Mit seiner steigenden Bekanntheit taten es ihm immer mehr Briefpartner gleich. So ist uns ein enormes Briefkorpus überliefert, das „einige Jahrzehnte nach Erasmus' Tod als die bedeutsamste humanistische Briefsammlung nördlich der Alpen" 10 galt. Zu Lebzeiten war Erasmus dadurch „gleichsam ein Kommunikationszentrum der Humanisten Europas geworden". ${ }^{11}$ Allein zwischen 1495 und 1520 verfasste er über tausend Briefe, am 14. März 1531 gar mehr als sechzig

${ }^{9}$ Aus der Fülle an biographischen Studien zu Erasmus sei hier nur stellvertretend verwiesen auf: C. Galle, Hodie nullus - cras maximus. Berühmtwerden und Berühmtsein im frühen 16. Jahrhundert am Beispiel des Erasmus von Rotterdam (Münster, 2012); W. Ribhegge, Erasmus von Rotterdam (Darmstadt, 2010); L. E. Halkin, Erasmus von Rotterdam. Eine Biographie (Zürich, 1989); C. Augustijn, Erasmus von Rotterdam. Leben - Werk - Wirkung (München, 1986), sowie die zahlreichen Studien von polnischer Seite, besonders von Henryk Barycz, Stanisław Łempicki und Maria Cytowska, die hier indirekt rezipiert werden.

${ }^{10}$ K. A. Neuhausen, „Der Brief als ,Spiegel der Seele' bei Erasmus“, in: Wolfenbütteler Renaissancemitteilungen 10, hrsg. v. A. Buck (Wiesbaden, 1986), S. 97-110, hier: S. 102. Zur Korrespondenz des Erasmus vgl. auch C. L. Heesakkers, "Correspondance d'Érasme“, in: Les grands intermédiaires culturels de la République des Lettres. Études de réseaux de correspondances du XVIe au XVIIIe siècles, hrsg. v. C. Berkvens-Stevelinck, H. Bots, J. Häseler (Paris, 2005), S. 29-60; L. Voet, „Erasmus and his correspondents“, in: Erasmus of Rotterdam. The Man and the Scholar. Proceedings of the Symposium held at the Erasmus University, Rotterdam, 9-11 November 1986, hrsg. v. J. Sperna Weiland, W. Th. M. Frijhoff (Leiden et al., 1988), S. 195-202.

11 W. Ribhegge, „Kontakte und Kontroversen. Martin Luther, Erasmus von Rotterdam und Thomas More“, in: Europa: Wiege des Humanismus und der Reformation. 5. Internationales Symposion der "Amici Thomae Mori“ 20. bis 27. Mai 1995 in Mainz, hrsg. v. H. Boventer, U. Baumann (Frankfurt am Main et al., 1997), S. 111-129, hier: S. 116; vgl. dazu auch Galle, op. cit., S. 87-99, $171-194$. 
Briefe. ${ }^{12}$ Chris Heesakkers hat daher das Diktum vom „Erasmus epistolographus" ${ }^{13}$ geprägt. Die 666 Korrespondenzpartner des Erasmus entstammten fünfzehn verschiedenen Ländern Europas, ${ }^{14}$ wie auf Grundlage der mustergültig erstellten Edition von Percy Stafford Allen ermittelt werden kann. Es handelt sich dabei um ein zwölfbändiges Werk, das allein durch seine Qualität den zweiten Grund darstellt, weshalb sich die Korrespondenz des Erasmus für die Untersuchung anbietet. ${ }^{15}$ Für wenige Zeitgenossen liegen vergleichbare Editionen vor.

Wenden wir uns damit sogleich der Auswertung zu: Die Erasmus-Korrespondenz weist dreißig polnische oder in Polen lebende Briefpartner auf, wie 91 überlieferte Briefe bezeugen. Da es sich zum Teil um Antworten auf nicht erhaltene Stücke handelt, muss das tatsächliche Korpus größer geschätzt werden, doch sind auch auf dieser Basis repräsentative Beobachtungen möglich. Nur aus drei Orten des polnischen Königreichs wurden Briefe an Erasmus entsandt aus Krakau (17), Piotrków (2) und dem ca. $150 \mathrm{~km}$ nordöstlich von Krakau, am Rande des Heiligkreuzgebirges gelegenen Bodzentyn (1). ${ }^{16}$ Wenngleich Schlesien im 16. Jahrhundert nicht zu Polen gehörte, ist es unverzichtbar, zumindest auch für die inhaltliche Auswertung die Briefe mit jenen Korrespondenzpartnern zu berücksichtigen, die in Breslau und Kremsier lebten, da sie wesentliche Informationen über die Stimmung in Polen bereithalten. ${ }^{17}$ Den Anfang der ins Königreich Polen gesandten Schreiben macht ein Brief von

12 Galle, op. cit., S. 97-98.

${ }^{13}$ Heesakkers, op. cit., S. 29-30.

${ }^{14}$ Galle, op. cit., S. 98; Voet, op. cit., S. 196-197.

15 Vgl. Opus Epistolarum Des. Erasmi Roterodami, 12 Bde., hrsg. v. P. S. Allen (Oxford, 1906-1958 [im Folgenden: Allen]). Auf dieser Grundlage wurde auch eine englischsprachige Übersetzung angefertigt: The Correspondence of Erasmus, 12 Bde., hrsg. v. R. A. B. Mynors et al. (Toronto, 1974-2003). Eine polnische Übersetzung der Korrespondenz zwischen Erasmus und seinen polnischen Briefpartnern liegt ebenfalls vor: Korespondencja Erazma z Rotterdamu z Polakami, hrsg. v. M. Cytowska (Warszawa, 1965).

${ }^{16}$ Die übrigen Briefe wurden nicht nur von Erasmus verfasst, sondern auch von Polen an ihn adressiert, allerdings aus Gebieten außerhalb Polens. Ferner sind beispielsweise für die Korrespondenz mit Briefpartnern in Breslau vier und in Kremsier zwei relevante Zeugnisse nachweisbar (vgl. Anm. 23). Vgl. dazu auch Voet, op. cit., S. 197.

${ }^{17}$ Dies gilt insbesondere für die Briefe von Johann und Stanislaus Turzo und gerade für den Zeitraum vor 1523, bevor Erasmus Briefverkehr mit Polen unterhielt. 
Erasmus an Justus Ludovicus Decius, auf den 24. Oktober 1523 datiert; ${ }^{18}$ der letzte Brief stammt von Joseph Tectander, der ihn am 16. August 1536 verfasste, ohne zu wissen, dass Erasmus viereinhalb Wochen zuvor verstorben war. Bereits aus diesen Angaben kann geschlossen werden, dass der Kontakt mit Polen - gemessen an der Biographie des Erasmus wie auch im Vergleich zu seiner Korrespondenz in zahlreiche andere Länder Europas - erst relativ spät zustande kam. Schon längst war er eine gefeierte Autorität, ${ }^{19}$ hatte sich u.a. mit seinen Anthologien, den ,Adagia', oder mit dem ,Lob der Torheit' als Humanist einen Namen gemacht und mit seiner Ausgabe des Neuen Testaments in griechischer Sprache in der Theologie für Aufsehen gesorgt. ${ }^{20}$ Dass die meisten an ihn adressierten Briefe aus Polen in Krakau verfasst wurden, ${ }^{21}$ erklärt sich bereits daraus, dass hier das Zentrum des Humanismus und vermutlich jeglichen Wissenschaftsbetriebs im Königreich war. Dennoch scheint sich die Korrespondenz erst langsam entwickelt zu haben, um ab 1525 signifikant zuzunehmen. Der Briefverkehr gestaltet sich nach Jahren wie folgt: ${ }^{22}$

${ }^{18}$ Vgl. Allen V, Nr. 1393. Die Aussage Jan Papiórs, der Kontakt des Erasmus nach Polen lasse sich in der Korrespondenz erst im Jahr 1523 nachweisen, ist damit zutreffend. Vgl. idem, „Polenmotive und -themen im deutschen Schrifttum - zum Kulturdiskurs im 15. und 16. Jahrhundert", in: Polnisch-deutsche Wechselbeziehungen im zweiten Millennium, Tl. 1: Zur polnisch-deutschen Kulturkommunikation in der Geschichte - Materialien, hrsg. v. J. Papiór (Bydgoszcz, 2001), S. 72-116, hier: S. 88.

19 Vgl. Galle, op. cit., S. 266, 280, 386-387.

${ }^{20} \mathrm{Zu}$ Erscheinungsjahren und Druckorten dieser Titel vgl. Galle, op. cit., S. 393-394, 402-403, 420-421.

${ }^{21}$ Vgl. dazu J. Glomski, „Erasmus and Cracow (1510-1530)“, Erasmus Studies 17 (1997), S. 1-18.

${ }^{22}$ Für die Jahre von 1518 bis 1536 sind folgende Briefe für den Kontakt zwischen Erasmus und polnischen oder in Polen lebenden Briefpartnern zu nennen (alle Angaben für die von Allen herausgegebene Edition [vgl. Anm. 15] folgen dem Muster: Allen, Bandnummer, Briefnummer): 1523: Allen V, Nr. 1393; 1524: Allen VI, Nr. 1502; 1525: Allen VI, Nr. 1572, 1593, 1602, 1622, 1629, 1652; 1526: Allen VI, Nr. 1660, 1662, 1672, 1674, 1698, 1751-1754; 1527: Allen VII, Nr. 1803, 1810, 1819-1822, 1824-1826, 1855, 1915-1919; 1528: Allen VII, Nr. 1952-1954, 1958, 2030-2035, 2078; 1529: Allen VIII, Nr. 2091, 2173-2177, 2201; 1530: Allen VIII, Nr. 2351; Allen IX, Nr. 23752377; 1531: Allen IX, Nr. 2520-2521, 2533, 2545, 2548-2550, 2584; 1532: Allen IX, Nr. 2600-2601, 2606; Allen X, Nr. 2643, 2658, 2664, 2713, 2717-2718, 2746; 1533: Allen X, Nr. 2776, 2780, 2811, 2861-2862, 2874; 1534: Allen X, 2911; Allen XI, Nr. 2960-2961; 1535: Allen XI, Nr. 3000, 


\section{Briefanzahl}

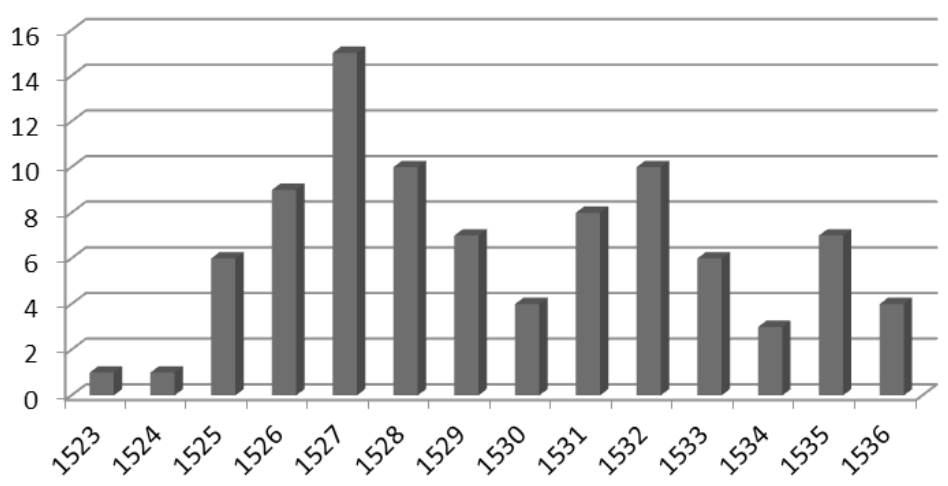

Für die früheren Jahre, d.h. ab 1518, sind zehn Briefe nachweisbar, die Erasmus mit den Turzo-Brüdern Johann und Stanislaus sowie mit Caspar Ursinus gewechselt hat, die sich in Schlesien aufhielten. ${ }^{23}$ Aufgrund ihrer Beziehung ins polnische Königreich ist die Vorstellung nicht abwegig, dass sich der Kontakt zu Erasmus konzentrisch ausbreitete und sich von Breslau aus den Weg nach Polen bahnte. Dieser Lesart folgend lässt sich die Korrespondenz auf den Verlauf der reformatorischen Bewegung beziehen, da der Kontakt zu Erasmus zunächst von schlesischer Seite aufgenommen wurde - und das zu einem Zeitpunkt, als die volkssprachliche Version von Luthers Ablassthesen in Gestalt des ,Sermon von Ablass und Gnade' erstmals über die Stadtgrenzen Wittenbergs hinaus für Aufsehen sorgte und durch die rasche Abfolge von Nachdrucken reichsweit und vermutlich auch darüberhinaus Beachtung fand. Der darauf folgende, rasante Anstieg von Briefen in Polen lebender Personen ab Mitte der 1520er Jahre lässt sodann genauso an den Streit um die Willensfreiheit des Menschen denken, den Erasmus und Luther auch öffentlichkeitswirksam führten, wie an den Bauernkrieg oder den erstarkenden linken Flügel

3010, 3014, 3038, 3046, 3049, 3066; 1536: Allen XI, Nr. 3089, 3121, 3137-3138.

${ }^{23}$ Es handelt sich dabei um die Briefe von Johann Turzo, die er um den 20. Juni 1518 sowie den 1. Dezember 1519 an Erasmus adressierte (vgl. Allen III, Nr. 850, bzw. Allen IV, Nr. 1047), von Ursinus, datiert auf den 20. Juni 1518 (vgl. ibidem, Nr. 851), sowie von Stanislaus Turzo vom 10. April 1522 (vgl. Allen V, Nr. 1272). Erasmus seinerseits verfasste an sie sechs Briefe (Allen III, 943-944; Allen IV, Nr. 1137, 1242-1243; Allen V, Nr. 1267). 
der Reformation um die Täufer in Münster, um Thomas Müntzer oder Andreas Karlstadt. Mögen daneben die Bekenntnisbildung im Zusammenhang des Augsburger Reichstags 1530 oder die zeitgleich stattfindenden Kappeler Kriege in der Eidgenossenschaft verantwortlich sein für einen neuerlichen Anstieg der Korrespondenz zu Beginn der 1530er Jahre? - So schlüssig diese Annahmen auf den ersten Blick erscheinen, vermag doch erst eine inhaltliche Auswertung des Briefwechsels Aufschluss zu geben hinsichtlich der Frage, welche Bedeutung der reformatorischen Bewegung in den Briefen zwischen Erasmus und seinen polnischen oder in Polen lebenden Briefpartnern zukam. Dabei können die Jahre von 1518 bis zum Tode des Erasmus in vier Phasen eingeteilt werden.

1. Die Jahre von 1518 bis 1524 :

Beunruhigung und Verachtung

Gleich der erste Brief verdient Beachtung - und das wegen seines Inhalts genauso wie wegen des Verfassers: Wie erwähnt wurde er von Johann Turzo ${ }^{24}$ geschrieben, ${ }^{25}$ der seit 1506 Bischof von Breslau war. Dass Erasmus hier von einem Mitglied der kirchlichen Elite Schlesiens kontaktiert wurde, zeugt für sich bereits von der öffentlichen und internationalen Bedeutung, über die der Humanistenfürst zu dieser Zeit verfügte. Johann, der einer einflussreichen ungarischen Familie entstammte, hatte vor einem Studienaufenthalt in Italien in Krakau studiert und unterhielt Zeit seines Lebens intensive Beziehungen nach Polen. Gemeinsam mit seinem Bruder Stanislaus, ${ }^{26}$ der wie der dritte Turzo, Alexius, ${ }^{27}$ Briefpartner des Erasmus wurde, war er von Jakob Piso $^{28}$ unterrichtet und mit erasmischen Texten bekannt gemacht worden, als sich beide am Königshof in Buda aufhielten. Dies erklärt auch, wieso er im vorliegenden Brief in erster Linie den Humanisten Erasmus, weniger den Theologen anschrieb. Auch wenn er mit den

${ }^{24} \mathrm{Zu}$ Johann Turzo vgl. H. Kowalska, s.v. „Johannes (I) Thurzo, 30 April 1437 - 10 October 1508“, in: Contemporaries of Erasmus. A Biographical Register of the Renaissance and Reformation, 3 Bde., hrsg. v. P. G. Bietenholz (Toronto, Buffalo and London, 1985-1987), hier: Bd. 3, S. 323.

${ }^{25} \mathrm{Vgl}$. Allen III, Nr. 850.

${ }^{26}$ Vgl. dazu L. Domonkos, s.v. „Stanislaus Thurzo, d 16 April 1540“, in: Contemporaries of Erasmus 3, S. 324-325.

$27 \mathrm{Vgl}$. dazu L. Domonkos, s.v. „Alexius Thurzo, d 25 January 1543“, in: Contemporaries of Erasmus 3, S. 322-323.

${ }^{28} \mathrm{Zu}$ Piso vgl. u.a. L. Domonkos, s.v. „Jacobus Piso of Medgyes, d March 1527“, in: Contemporaries of Erasmus 3, S. 94-95. 
unter Humanisten üblichen Höflichkeitsfloskeln einsetzte, brachte er seine tiefe Bewunderung für Erasmus zum Ausdruck, den er sowohl durch sein Oeuvre als auch durch Bekannte kenne. Zwar bewundere er viele berühmte Gelehrte, doch erscheine ihm Erasmus unter diesen deshalb als eine außergewöhnliche Gestalt, da er es verstehe, die lateinische Beredsamkeit des Humanismus mit der reinen christlichen Lehre in Verbindung zu bringen. ${ }^{29}$ Für Johann Turzo war es daher vor allem der biblische Humanismus, den Erasmus begründet hatte, und der ihn zu seiner Kontaktaufnahme veranlasste. Dies deutet darauf hin, dass unter Gelehrten östlich des Reichs nicht allein die humanistischen Werke des Erasmus bekannt waren, sondern genauso seine theologischen, allen voran vermutlich sein Neues Testament. ${ }^{30}$ Daneben ist dieser Brief ein wichtiges Zeugnis, da Turzo wohl nicht nur aus persönlicher Verehrung darauf verwies, dass Erasmus hier viele Anhänger habe, schließlich nannte er namentlich den erwähnten Jakob Piso, der auch den ungarischen König Ludwig unterrichtet hatte, und Caspar Ursinus ${ }^{31}$, der sogar ein Gedicht aus Anlass des Geburtstages des Erasmus verfasst habe. ${ }^{32}$ Dies war zugleich der

${ }^{29}$ Vgl. Allen III, Nr. 850, S. 343.5-8: „Nam cum omnium qui ingenii laboribus illustres reliquis mortalibus prestant, nunquam non fuerim studiosus, tum eorum qui cum Romana eloquentia Christiane fidei puritatem copulavere, observantissimus videri cupiam."

${ }^{30}$ Dank des europaweiten humanistischen Netzwerks verfügten manche Polen schon lange vor den ersten Briefen an Erasmus über Kontakte in andere Länder. Vgl. dazu K. Baczkowski, „Humanismus in Krakau und Wien um die Wende vom 15. zum 16. Jahrhundert", in: Metropolen und Kulturtransfer im 15./16. Jahrhundert. Prag - Krakau - Danzig - Wien, hrsg. v. A. Langer, G. Michels (Stuttgart, 2001), S. 53-64; M. Włodarski, „Polen und Basel - kulturelle und literarische Verbindungen im 16. Jahrhundert", in: Der polnische Humanismus und die europäischen Sodalitäten. Akten des polnisch-deutschen Symposions vom 15.-19. Mai 1996 im Collegium Maius der Universität Krakau, hrsg. v. S. Füssel, J. Pirożyński (Wiesbaden, 1997), S. 91-100. Ganz allgemein zum Humanismus in Polen vgl. H. B. Segel, Renaissance Culture in Poland. The Rise of Humanism, 1470-1543 (New York, 1989); zur Rezeption des Erasmus in Polen vgl. C. Backvis, „La fortune d'Érasme en Pologne“, in: Colloquium Erasmianum. Actes du Colloque International réuni à Mons du 26 au 29 octobre 1967 à l'occasion du cinquième centenaire de la naissance d'Érasme, hrsg. v. Mons Centre Universitaire de l'État (Mons, 1968), S. 173-202.

${ }^{31} \mathrm{Zu}$ Ursinus vgl. M. Erbe, P. G. Bietenholz, s.v. „Caspar Ursinus Velius of Świdnica, d 5 March 1539“, in: Contemporaries of Erasmus 3, S. 356-357.

${ }^{32} \mathrm{Vgl}$. Allen III, Nr. 850, S. 343.15-344.20: „habes enim complures vel in his locis eximii ingenii tui miratores nominisque tui clarissimi precones egregios. Inter quos Iohannes Piso extat olim tibi Rome cognitus, Regis Ludovici 
Grund, weshalb sich auch Ursinus sodann an Erasmus wandte. ${ }^{33}$ Nach dem Studium in Italien war er sowohl zum ,poeta laureatus als auch von seinem Gönner, Bischof Johann, zum Kanoniker in Breslau ernannt worden und bat Erasmus nun ebenfalls um Freundschaft. ${ }^{34}$ Zunächst allerdings entschuldigte er sich dafür, dass sein Geburtstagsgedicht vom Korrektor gleich zum Druck gegeben worden war, ohne dass er Erasmus im Vorfeld um Erlaubnis hatte bitten können. ${ }^{35}$ Mit dem Brief sandte er ihm nun auch ein Exemplar des gedruckten Gedichts. Erasmus, gerührt von den freundlichen Kontaktaufnahmen, bedankte sich überschwänglich und es entwickelte sich eine rege Korrespondenz, die geprägt ist von gegenseitigen Danksagungen und Ehrbezeugungen. ${ }^{36}$ In diesem Zusammenhang brachte Johann Turzo ein weiteres Mal seine Überzeugung zum Ausdruck, dass es die Leistung des Rotterdamers sei, dass sowohl die freien Künste in Blüte stünden als auch eine reine Theologie, beides habe er allein zu Wege gebracht und beide führe er nach wie vor an. Um seinen Worten Nachdruck zu verleihen, sandte er Erasmus auch vier Glasgefäße, eine Zobelmütze sowie fünf Goldstücke, die in den Minen der Familie Turzo abgebaut worden waren. ${ }^{37}$ Als Erasmus sich mit seinem nächsten Schreiben vom 31. August 1520 bedanken wollte, war Johann Turzo bereits seit einigen Wochen verstorben. ${ }^{38}$ Ein knappes Vierteljahr später wandte sich Erasmus daher an dessen Bruder Stanislaus, um ihm sein Beileid auszusprechen. Wie aus dem Schreiben hervorgeht, hatte er in Brüssel durch Hieronymus Łaski ${ }^{39}$ und Michael Sander, ${ }^{40}$ dem Probst des Breslauer Domkapitals, vom

Hungarie in litteris preceptor, tum Caspar Ursinus Velius, phalecii illius author qui in natalem tuum est editus".

${ }^{33}$ Vgl. ibidem, Nr. 851.

${ }^{34}$ Vgl. ibidem, S. 346.44-52.

${ }^{35}$ Vgl. ibidem, S. 345.17-22.

36 Vgl. ibidem, Nr. 943-944; Allen IV, Nr. 1047, 1137.

37 Vgl. Allen IV, Nr. 1047, S. 134-135 (datiert auf 1. Dez. 1535), dort S. 134.25-27: „tum syncere illius quoque theologie puritas et sanctissima studia prope ad interitum redacta, te parente, te duce, veluti renata toto orbe reflorescant.“ Vgl. ibidem, S. 135.34-37: „munus tibi mitto, non magni sane precii: quatuor horologia inquam, vitreis vasculis exigua, pulvisculoque paulatim delabente horas dimetientia; quorum usus, opinor, clepsydram nostro seculo equat.“

38 Vgl. ibidem, Nr. 1137.

$39 \mathrm{Zu}$ Hieronymus Łaski vgl. M. Cytowska, s.v. „Hieronim Łaski, 27 November 1496 - 22 December 1541“, in: Contemporaries of Erasmus 2, S. 294-296.

${ }^{40}$ Vgl. P. G. Bietenholz, s.v. „Michael Sander, died c September 1529“, in: Contemporaries of Erasmus 3, S. 193. 
Tode des Bischofs erfahren. ${ }^{41}$ Auch Stanislaus hatte die Bischofsweihe empfangen und stand von 1497 bis 1520 der Diözese im mährischen Olmütz vor. Zuvor hatte er in Krakau studiert und einige Zeit in Rom verbracht. Als Primas von Mähren half er 1509 bei der Krönung Ludwigs II. zum böhmischen König und empfing diesen in seinem Palast in Kremsier im folgenden Jahr genauso wie Sigismund von Polen 1516. Wie sein älterer Bruder Johann war auch Stanislaus ein Förderer der Wissenschaften. So hatte er Ulrich von Hutten bei seiner Reise durch Mähren ein Pferd sowie Reisegeld zur Verfügung gestellt. ${ }^{42}$ Auch Erasmus muss er Geschenke gemacht haben, schließlich bedankte dieser sich in seinem nächsten Schreiben ${ }^{43}$ bei ihm und bezeichnete Stanislaus im folgenden Jahr bereits als seinen Patron. ${ }^{44}$ Daneben ist dieser Brief auch aus einem anderen Grund ein wichtiges Zeugnis innerhalb der Korrespondenz zwischen Erasmus und den schlesischen Briefpartnern, weil in ihm nämlich das erste Mal die kirchliche Situation im Reich zum Thema gemacht wurde. Erasmus zeigt sich beunruhigt darüber, dass sich zwei Lager gebildet hatten, von denen das eine die Freiheit des Evangeliums anstrebte, das andere sich beharrlich dagegen wehrte. Seiner Ansicht nach sollten die Fürsten daher die Angelegenheit obrigkeitlich regeln. Für ihn selbst habe die Entwicklung auch ganz persönlich Folgen: Obwohl er sich bislang noch nie mit einem Anhänger Luthers habe verständigen können, werde er nun selbst als Lutheraner verdächtigt, weil sich in zahlreichen reformatorischen Flugschriften Auszüge aus seinen Werken wiederfänden. Während er mittlerweile von beiden Lagern als häretisch angesehen werde, drängten ihn viele, besonders Fürsten, gegen Luther publizistisch vorzugehen. ${ }^{45}$ Vermutlich suchte Erasmus, sich

${ }^{41}$ Vgl. Allen IV, Nr. 1242, S. 598-602, hier: S. 600.24-601.29: „Primus illius obitum obnunciavit Bruxellae Hieroslaus Lascanus, Polonorum legatus, iuvenis eleganter doctus. Aegre credebam, licet affirmanti. Mox Zanderus, praepositus Vratislaviensis, mihi reddidit animum, confirmans se ex amicorum literis certo scire Turzonem convaluisse. Sed idem paulo post diversis acceptis literis, ex falso gaudio me in verum ac certum luctum coniecit."

42 Vgl. dazu ibidem, S. 599.

${ }^{43}$ Vgl. ibidem, Nr. 1243 (datiert auf 22. Nov. 1521).

${ }^{44}$ Vgl. Allen V, Nr. 1267, S. 31-32 (datiert auf 21. März 1522), hier: S. 31.4-32.6: „noluimus tamen hominem absque nostris litteris abire, quibus testificaremur animum ad omnia paratissimum officia quae humilis sed devotus cliens debet optimo optimeque merito patrono."

45 Vgl. ibidem, Nr. 1267, S. 32.13-28. Stanislaus antwortete am 10. April 1522 vermutlich aus Kremsier, indem er sich bei Erasmus überschwänglich für das 
auch dieser Situation zunächst zu entziehen, da sein Umzug nach Basel kein halbes Jahr zuvor erfolgt war. Es verwundert daher nicht, dass er in seinem nächsten Brief die Frömmigkeit der Polen lobte, ${ }^{46}$ die bislang noch in keiner Weise von der reformatorischen Bewegung im Reich beeinflusst worden war. Der Empfänger dieses Schreibens - des ersten, das er tatsächlich ins polnische Königreich sandte - war Justus Ludovicus Decius, der aus dem Niederelsass stammte, seit Mai 1520 aber als Sekretär des polnischen Königs tätig war. ${ }^{47} 1522$ stattete er Erasmus in Basel einen Besuch ab und besorgte ein halbes Jahr vor dem genannten Schreiben in Krakau den Druck von ,De conscribendis epistolis' des Erasmus. In der Folgezeit avancierte Decius zu einem Kontaktvermittler zwischen dem Rotterdamer und seinen polnischen Verehrern. ${ }^{48} \mathrm{Im}$ vorliegenden Brief hob Erasmus nun die in Polen überaus günstigen Verhältnisse in Literatur und Recht hervor, daneben auch die Frömmigkeit und Sitten, in denen das polnische Volk es mit allen anderen aufnehmen könne. Er sehe es als Glücksfall an, dass obendrein noch der erlauchte Sigismund die Herrschaft innehabe, der mit seinen siegreichen Kriegen gegen Tartaren und Russen die Christenheit verteidigt habe. ${ }^{49} \mathrm{Da}$ es sich bei diesem Brief zugleich um seine Widmungsrede für die Paraphrase über das

vorige Schreiben bedankte, ihm vier Goldstücke sandte sowie seine Hilfe anbot (vgl. ibidem, Nr. 1272).

46 Vgl. ibidem, Nr. 1393. Vgl. allgemein dazu auch J. Koryl, „Eramus among his Polish Correspondents. Religious Identity in the Age of Confessionalization“, in: Respublica Litteraria in Action. Religion and Politics, hrsg. v. A. Skolimowska with collaboration of K. Jasińska-Zdun (Warsaw, 2012), S. 143-175; H. Louthan, „A Model for Christendom? Erasmus, Poland and the Reformation“, Church History 83 (2014), S. 18-37.

${ }^{47}$ Aufgrund seiner Kenntnisse in Handel, Finanzen und Bergbau trat Decius ins Krakauer Bankhaus von Jan Boner ein, einem Handelspartner der Augsburger Fugger. Vgl. dazu Allen V, S. 343-344. Zur Biographie des Justus Decius vgl. M. Cytowska, s.v. „Justus Ludovicus Decius of Wissembourg, c 1495 26 December 1545“, in: Contemporaries of Erasmus 1, S. 380-382.

${ }^{48} \mathrm{Vgl}$. dazu Allen V, S. 343-344.

49 Vgl. ibidem, S. 344.18-345.21: „Genti gratulor, quae quum olim ob barbariem male audierit, nunc et literis et legibus et moribus et religione, et si quid aliud est quod a barbariei probro vindicet, sic floreat ut cum praecipuis ac laudatissimis nationibus certare possit." Vgl. ibidem, S. 345.27-33: „quibus omnibus latissime imperat a Vistula flumine ad Tauricam Chersonesum, a mari Balthico ad Carpathum montem Sigismundus Rex, quum omnibus magno Principe dignis dotibus excellens, tum multis ac magnis ex hoste Tartaro Moschoque relatis victoriis clarus: quibus haud scio an ullae magis fuerint necessariae tuendis Christianae ditionis limitibus." 
Vaterunser handelte, um die Decius gebeten hatte, ${ }^{50}$ ist von einer größeren Verbreitung des Inhalts auszugehen. Erst zwölf Monate später sandte Erasmus wieder einen Brief nach Polen, als er Hieronymus Łaski seinen Text ,Modus orandi Deum' widmete und mit einem persönlichen Schreiben versah. ${ }^{51}$ Hieronymus, der polnische Baron, war gemeinsam mit seinen Brüdern Johann und Stanislaus Erasmus bekannt. ${ }^{52}$ Das hier an ihn gerichtete Schreiben besteht nur aus wenigen Zeilen, in denen Erasmus ihm insbesondere für geleistete Wohltaten dankte und sich mit seinem Text erkenntlich zeigen wollte. Mit dem kleinen Werk, das rasch ins Französische, Deutsche und Niederländische übersetzt wurde, wollte sich Erasmus gegen Luthers Ablehnung der Heiligenverehrung richten. ${ }^{53}$ Deutlicher brachte er seine Verachtung gegenüber den Evangelischen jedoch in einem Schreiben an den Schlesier Ursinus vom 14. November 1524 zum Ausdruck, in dem er diesem zunächst zur neuen Anstellung an der Wiener Universität gratulierte, um sodann von ihrem gemeinsamen Bekannten Michael Bentinus zu berichten. Dieser war zuvor ein Gehilfe des Basler Druckers Froben und vermutlich spielte auch die Unzufriedenheit des Erasmus über die Arbeit des Bentinus bei der Druckerstellung der ,Adagia' eine Rolle für die abfälligen Bemerkungen über ihn: Wie Erasmus berichtet, ziehe dieser durch die Gegend und predige überall das Evangelium sowie das übrige Reformatorengerede, nämlich dass der Papst der Antichrist und dessen Lehren ketzerisch seien. Nun habe er geheiratet und mit neuem Geist erfüllt wolle er sich in Frankreich eine kleine Gemeinde

${ }^{50}$ Vgl. ibidem, S. 344.1-14, 345.35. Zu den an Polen und in Polen lebenden Persönlichkeiten, denen Erasmus Texte widmete, vgl. Papiór, „Polenmotive und -themen im deutschen Schriftum“, S. 84, Anm. 16.

${ }^{51} \mathrm{Vgl}$. Allen V, Nr. 1502, S. 559-560.

52 Vgl. ibidem, S. 560.8-9. Zu Johann Łaski vgl. H. P. Jürgens, Johannes a Lasco in Ostfriesland. Der Werdegang eines europäischen Reformators (Tübingen, 2002), bes. S. 46-91 zum Verhältnis zwischen Johann und Erasmus. Vgl. auch Johannes a Lasco (1499-1560). Polnischer Baron, Humanist und europäischer Reformator, hrsg. v. C. Strohm (Tübingen, 2000), darin besonders: N. Mout, „Erasmianischer Humanismus und reformierter Protestantismus zur Zeit a Lascos“, S. 21-34; O. Bartel, „Johannes a Lasco und Erasmus von Rotterdam“, Lutherjabrbuch 32 (1965), S. 48-66.

53 Vgl. den auf den 22. März 1525 datierten Brief des Erasmus an Kardinal Jean de Lorraine. Allen VI, Nr. 1559, S. 52-55, hier: S. 55.120-122: „missuri libellum De modo orandi Deum, in quo adversus eundem asserimus invocationem Sanctorum, si senserimus hoc studium nostrum esse gratum." 
suchen. ${ }^{54}$ Erasmus leitete diese Schilderung mit den Worten ein, er wolle Ursinus noch etwas Lächerliches mitteilen. ${ }^{55}$ Auch wenn sich diese Worte vor allem gegen Bentinus richteten, kommt darin die Haltung des Erasmus gegenüber den reformatorischen Lehren so deutlich zum Ausdruck wie selten in anderen Briefen dieser Jahre. Natürlich ärgerte er sich darüber, dass er ungefragt von Anhängern Luthers zitiert wurde und auf diese Weise in den Verdacht geriet, die reformatorische Bewegung zu unterstützen. Dennoch aber ließ er den mehrfachen Bitten und Aufforderungen, sich öffentlich zu positionieren und gegen die Reformatoren zu schreiben, keine Taten folgen, so dass seine wahre Haltung lange unklar blieb. Tatsächlich aber sah er die Entwicklung als Bedrohung an und das in einem Maße, dass er sich zum Umzug nach Basel veranlasst sah. Insofern sind die Stellungnahmen zur Reformation, wie sie sich vor allem in den von Erasmus verfassten Briefen finden, geprägt von der Wahrnehmung einer Bedrohung sowie einer Geringschätzung gegenüber einer Reihe von Lutheranern. In den an Erasmus gerichteten Briefen finden sich bis zum Ausgang des Jahres 1524 keinerlei Bezugnahmen auf die reformatorische Bewegung. Daher wird der Blick der in Polen lebenden Korrespondenzpartner auf die Entwicklung im Reich maßgeblich von der Sicht des Erasmus geprägt gewesen sein.

2. Die Jahre von 1525 bis 1528: Gegenwehr und Verachtung

Die nächsten dreieinhalb Jahre bis Sommer 1528 weisen in der hier ausgewerteten Korrespondenz die meisten erhaltenen Briefe auf. Dabei wird die reformatorische Bewegung - nun auch aus Polen - viel häufiger zum Thema gemacht als zuvor. Nach drei Briefen, in denen Erasmus zunächst gegenüber Stanislaus Turzo die Absicht erklärte, ihm aufgrund seiner Freundschaft die Edition eines Plinius-Textes widmen zu wollen, im zweiten Caspar Ursinus ihm einen Bericht aus Wien gab und sich sodann wiederum Erasmus an Alexius Turzo richtete, um ihm als Dank für seine Förderung der Wissenschaft zwei Plutarch-Abhandlungen zukommen zu lassen, ${ }^{56}$ schrieb er

${ }^{54}$ Vgl. Allen V, Nr. 1514, S. 577-578, hier: S. 578.1-3, 15-22. Zu Bentinus vgl. V. Brown, P. G. Bietenholz, s.v. „Michael Bentinus, d November 1527“, in: Contemporaries of Erasmus 1, S. 123-124.

$55 \mathrm{Vgl}$. Allen V, Nr. 1514, S. 578.15.

${ }^{56}$ Es handelt sich dabei um Allen V, Nr. 1544 und Allen VI, Nr. 1557, 1572. Der an Stanislaus Turzo gerichtete Brief wurde sodann auch als Vorwort zu 
am 14. August an Krzysztof Szydłowiecki. ${ }^{57}$ Dieser entstammte einer hochangesehen polnischen Adelsfamilie und war gemeinsam mit den Kindern König Kasimirs IV. unterrichtet worden. 1515 war er zum polnischen Kanzler ernannt worden und brachte als solcher das im gleichen Jahr in Wien stattfindende Treffen zwischen Kaiser Maximilian und König Sigismund zu Wege. Als Vertrauter Sigismunds wurde er zudem zum Krakauer Präfekten ernannt. ${ }^{58}$ Er verfügte über beachtlichen Reichtum und trat als großzügiger Förderer von Literaten und Künstlern in Erscheinung. Vermutlich wandte sich Erasmus auf Anraten Johann Łaskis an Szydłowiecki, ${ }^{59}$ dem er mit dem Schreiben zugleich seine ,Lingua' zueignete. In diesem Text, der mehrfach u.a. ins Spanische, Flämische und Niederländische übersetzt wurde, setzt sich Erasmus mit der Macht der menschlichen Zunge, gemeint: der Sprache, auseinander und zeigt auf, wie sie in den Dienst von Gut und Böse gestellt werden kann. In dem als Vorrede verwendeten Schreiben an Szydłowiecki zählt er zunächst verschiedene Leiden auf, um letztlich den kranken Zustand der Christenheit anzusprechen, der gegenwärtig in Bränden, Spaltungen und Fesseln deutlich werde. ${ }^{60}$ Er selbst aber fühle sich nicht im Stande, daran fundamental etwas zu ändern, er könne lediglich mit Veröffentlichungen wie der ,Lingua' eine Form von Palliativmedizin anbieten. ${ }^{61}$ Es liegt auf der Hand, dass hier die Wirren des in weiten Teilen des Reichs tobenden Bauernkrieges leitend waren und sich Erasmus dazu veranlasst sah, Stellung zu beziehen. Gerade auch weil ihm lange der

seiner Ausgabe der ,Naturalis historia' des Plinius verwendet. Die für Alexius bestimmten Abhandlungen Plutarchs waren ,De non irascendo' und ,De curiositate ' und sie wurden ihm auf Drängen Jan Antonins gewidmet, der Erasmus in seinem Nierenleiden behandelt hatte. Im Gegensatz zu seinen beiden Brüdern wählte Alexius Turzo eine weltliche Laufbahn und war vor allem im Bergbaugewerbe aktiv. Vgl. dazu Allen VI, S. 70.

57 Vgl. Allen VI, Nr. 1593. Zu Szydłowiecki vgl. H. Kowalska, s.v. „Krzysztof Szydłowiecki, 1467 - 30 December 1532“, in: Contemporaries of Erasmus 3, S. 304-305.

${ }^{58}$ Vgl. Allen VI, Nr. 1593, S. 134-135.

59 Vgl. ibidem, S. 138.133-134.

${ }^{60}$ Vgl. ibidem, S. 135-138.

${ }^{61}$ Vgl. ibidem, S. 138.127-132: „Usturis, sectionibus, et compedibus quid hactenus profectum sit videmus. Nos, tametsi nec auctoritate nec eruditione prudentiaque praediti sumus, quantam morbi fatalis magnitudo requirit, tamen ad publicam orbis Christiani calamitatem ingemiscentes, qualecunque pharmacum attulimus, quo si malum hoc funditus tolli non potest, certe mitigetur." 
Vorwurf gemacht wurde, tatenlos zuzusehen und als intellektuelle Leitfigur zu lange zu schweigen, erklärte er hier öffentlich sein Verhalten. Dass dies in Polen entsprechend Aufnahme fand, bezeugt ein Brief an Andrzej Krzycki rund zwei Monate später. ${ }^{62}$ Dieser war Neffe des Krakauer Bischofs Piotr Tomicki ${ }^{63}$ und wurde nach dem Studium in Bologna enger Vertrauter des polnischen Königs. 1522 war er zum Bischof von Przemyśl geweiht worden. ${ }^{64}$ Nachdem er zunächst ein Befürworter der Ziele Luthers gewesen war, trat er nun als entschiedener Gegner in Erscheinung und verfasste mehrere Gedichte und Traktate gegen Luther. ${ }^{65}$ Der Grund für das Schreiben des Rotterdamers an ihn war, dass Stanislaus Łaski Erasmus ein Exemplar der ,In Luterum oratio' gezeigt hatte, in der Krzycki Kritik an Luther geübt und sich dabei intensiv auf Erasmus berufen hatte. ${ }^{66}$ Dieser Text ist beispielhaft dafür, dass die kirchliche Elite Polens die Entwicklung im Reich mit Besorgnis zur Kenntnis nahm. Dabei scheint der Verdacht, Erasmus könne ein verdeckter Lutheranhänger sein, hier keine Rolle zu spielen. Die Gründe sind wohl vor allem darin zu sehen, dass sich dieser Eindruck größtenteils auf die deutsche Öffentlichkeit

${ }^{62}$ Vgl. ibidem, Nr. 1629. In der Zwischenzeit sandte er noch Schreiben an Jan Antonin und Hieronymus Łaski (vgl. ibidem, Nr. 1602, 1622). Jan Antonin von Košice (ca. 1499 - ca. 1549) stammte gebürtig aus Nordungarn, hatte in Krakau und Padua studiert. Nach der Promotion zum Doktor der Medizin lebte er einige Jahre in Basel, wo er mit Erasmus in Kontakt kam. Über Ungarn siedelte er 1525 nach Krakau, wo er Anstellungen als Leibarzt der Bischöfe Piotr Tomicki und Piotr Gamrat sowie König Sigismunds I. fand. Hieronymus Łaski war der Bruder Johann Łaskis, der die vergangenen Monate im Hause des Erasmus gewohnt hatte. Zu Krzycki vgl. H. Kowalska, s.v. „Andrzej Krzycki, 1482 - 10 May 1537“, in: Contemporaries of Erasmus 2, S. 275-278.

${ }^{63}$ Mit Tomicki nahm Erasmus am 12. Dezember 1527 auf Anraten Jan Antonins Kontakt auf (vgl. Allen VII, Nr. 1919). Nach der Promotion zum Doktor des kanonischen Rechts in Bologna fungierte Tomicki zunächst als Diplomat, dann als Vizekanzler unter König Sigismund I. So sehr er auch als Bischof von Krakau Humanisten unterstützte, so entschieden wandte er sich gegen die reformatorische Bewegung. 1523 verhinderte er sogar den Import von Büchern aus Deutschland und sorgte dafür, dass sich kein polnischer Student an einer deutschen Universität immatrikulieren konnte. Zu Tomicki vgl. M. Cytowska, s.v. „Piotr Tomicki, 1464 - 29 October 1535“, in: Contemporaries of Erasmus 3, S. 327-329.

${ }^{64} 1527$ wurde er noch Bischof in Płock und 1535 in Gniezno (vgl. Allen VI, S. 193).

${ }^{65}$ Vgl. ibidem, S. 193.

${ }^{66}$ Außerdem sandte Erasmus ihm ein Exemplar von Cuthbert Tunstalls ,De arte supputandi', für das sich Krzycki interessierte (vgl. ibidem, S. 194.11-15). 
begrenzte, da Erasmus insbesondere in volkssprachlichen Flugschriften als Gewährsmann Luthers präsentiert wurde. Für die Wahrnehmung des Wittenberger Reformators ist indes Krzyckis Antwortschreiben aufschlussreich. Im Dezember 1525 wandte er sich an Erasmus und nach den üblichen Bewunderungsfloskeln legt er sogleich dar, wieso er sich gegen Luther gerichtet habe: ${ }^{67}$ Zunächst habe er sich über dessen derbe Wortwahl aufgeregt, dann aber vor allem über dessen umfassende Kritik an allem Heiligen sowie den Bischöfen. Die Äußerungen Luthers veranlassten ihn zur Annahme, der Reformator sei von blindem Zorn erfüllt, und man beobachte in Polen das Geschehen mit großer Sorge. Es sei doch verwunderlich, so Krzycki, dass in der Menschheitsgeschichte stets jene Reiche untergingen, die kurz zuvor noch auf dem Zenit gestanden hätten. Daher erwarte er auch, dass Deutschland, das aufgrund seiner Kriegskunst, seiner Städte, Paläste, des Handels und der Bildung bewundert werde, bald zugrunde gehen werde. Für Erasmus empfinde er Mitleid, dass er in diesem Babylon leben müsse - und unterbreitet ihm eine Einladung nach Polen, dessen Vorzüge sodann aufgezählt werden. ${ }^{68}$

Dass es sich bei Krzycki weder um den einzigen polnischen Erasmus-Verehrer noch um den alleinigen Luther-Kritiker handelte, wird sogleich im nächsten Brief von Jan Antonin ${ }^{69}$ deutlich. $^{70}$ Dieser stammte zwar aus Ungarn, war aber jahrelang in Krakau tätig. In seinem Brief berichtet er, dass sich Alexius Turzo sehr über die ihm gewidmeten Schriften gefreut habe und nun beabsichtige, Erasmus

${ }^{67}$ Vgl. ibidem, Nr. 1652, S. 236-239, hier: S. 236.1-13, 237.66-238.73, 93-100.

${ }^{68}$ Krzycki zählt in diesem Zusammenhang die Beständigkeit des Landes im Vergleich zu Deutschland genauso auf wie die Tugenden des polnischen Königs, die Umsicht des Senats oder die Bildung der übrigen Verantwortungsträger. Wenn Erasmus sich nach Polen begäbe, würde man ihm gleich mehrere Drucker zur Verfügung stellen. Vgl. ibidem, S. 238.110-120: „Quare subduc te, rogo, quamprimum hiis turbis, teque hiis, precor, eripe flammis. Quid magis ex re tua et literarum feceris, quam ut ad nos quamprimum commigres, non video. Habemus regionem ex Germana quidem et Sarmatica constantem, sed quam libenter inhabitant etiam hii qui suas pre ceteris felices et fortunatas esse iactant. Habemus principem de cuius virtute, prudencia, benignitate, relligione [sic!] et rebus gestis dici satis non potest; habemus senatum sapientissimum, habemus satrapes non minus literarum quam armorum cultores; habemus ingenia non vulgaria, habemus et nobile Museon, habituri etiam Frobennios, si aderit Erasmus."

${ }^{69} \mathrm{Zu}$ Jan Antonin vgl. H. Kowalska, s.v. „Jan Antonini of Košice, c 1499 - c 1549“, in: Contemporaries of Erasmus 1, S. 63-64.

70 Vgl. Allen VI, Nr. 1660. 
ein Geschenk zukommen zu lassen. Ebenso habe er von Johann Henckel, ${ }^{71}$ dem Kaplan der ungarischen Königin, Geschenk und Brief zur Weiterleitung an Erasmus erhalten. Ferner lasse Krzysztof Szydłowiecki grüßen und ihm eine Goldarbeit als Geschenk zukommen und auch von Justus Decius und Andrzej Krzycki solle er Grüße übermitteln. Von Bischof Krzycki solle er zudem ausrichten, dass er gerne Erasmus jegliche Unterstützung zukommen lassen wolle, wann immer er sie benötige. Dabei handelte es sich offensichtlich nicht um den einzigen Korrespondenten, der für Erasmus eintrat. Schließlich, so berichtet Antonin weiter, habe es in Ungarn einige Kritiker des Erasmus gegeben, die in Rom von Aleander und Alberto Pio aufgewiegelt worden seien, doch habe Henckel sie sogleich mundtot gemacht. Für ihn selbst und Justus Decius sei Erasmus einem Gott gleich, den sie verehrten und für den sie Zuneigung empfänden wie für niemanden sonst. ${ }^{72}$ Vor diesem Hintergrund ist es nicht mehr überraschend, dass Antonin noch ergänzt, Luther sei in Krakau nicht gelitten. ${ }^{73}$ Die Korrespondenten des Erasmus standen treu zu ihm und lehnten mehrheitlich die Ziele Luthers ab. In dieser Hinsicht glaubten sie, mit dem Rotterdamer übereinzustimmen, doch agierten sie bereits entschiedener. Gegenüber Henckel, der in Ungarn für ihn eingetreten war, räumte Erasmus nämlich ein, dass er Luthers Kommentare zu den Psalmen und zum Vaterunser ebenso wie ,De quatuordecim spectris' hoch schätze, allerdings könne er dessen zunehmend aggressiver werdende Sprache nicht gutheißen. ${ }^{74}$ Da Luther sogar öffentlich gegen Könige Stellung bezogen und scheinbar jeglichen Anstand vergessen habe, sei er zwar mittlerweile froh, sich niemals zur reformatorischen Bewegung bekannt zu haben, doch befürchte er, dass mit Luther zugleich manches Positive, wie die Förderung der

${ }^{71}$ Vgl. L. Domonkos, s.v. „Johann Henckel of Levoča, d 5 November 1539“, in: Contemporaries of Erasmus 2, S. 175-176.

${ }^{72}$ Vgl. Allen VI, Nr. 1660, S. 249.10-250.36, 46-251.51, 64-65, 76-80. Für die Verehrung, die Erasmus entgegengebracht wurde, spricht ferner der nächste erhaltene Brief, den Jakob Piso ihm am 1. Februar 1526 aus Buda sandte. Darin wird berichtet, dass die beiden Brüder Turzo, Bischöfe in Breslau und Olmütz, große Zuneigung für Erasmus empfänden, weshalb er ihnen empfohlen habe, Erasmus brieflich zu kontaktieren. Außerdem habe Stanislaus Turzo den ungarischen König Ludwig II. besucht und beide hätten ein langes Gespräch über Erasmus und seine Werke geführt (vgl. ibidem, Nr. 1662, S. 253-256, bes. S. 255.54-67).

${ }^{73}$ Vgl. ibidem, Nr. 1660, S. 251.80-81: Cracoviae Lutherus pessime audit.

${ }^{74}$ Vgl. ibidem, Nr. 1662, S. 273-277, bes. S. 275.63-68. 
alten Sprachen und die freien Künste, zugunsten der Scholastik wieder untergehen könnte. ${ }^{75}$ Insofern sah Erasmus, wohl auch weil er die Entwicklung persönlich miterlebte, das Geschehen differenzierter als manche seiner Briefpartner in Polen. Unter den reformatorischen Gedanken konnte er durchaus das ein oder andere Positive finden, doch war für ihn in erster Linie die Vorgehensweise Luthers Anlass zur Distanzierung. Dies wird vor allem im Streit um die Willensfreiheit deutlich, den Erasmus mit Luther auch öffentlich austrug und der sich zumindest beiläufig auch in der Korrespondenz mit den polnischen Bekannten niederschlug. Wie bereits im Brief an Henckel vom 7. März 1526, ${ }^{76}$ so brachte er auch am 9. September gegenüber Bischof Krzycki seine Verärgerung zum Ausdruck. ${ }^{77}$ Dabei scheint es sich aber nicht in erster Linie um gegensätzliche Meinungen, als vielmehr um Luthers Verhalten gehandelt zu haben. Schließlich setzt Erasmus den Bischof über Luthers Attacken im Rahmen des Streits um die menschliche Willensfreiheit in Kenntnis, um sich dann aber breit darüber auszulassen, dass Luther, nachdem er ihn in aller Öffentlichkeit angegriffen habe, in einem Brief an ihn betont habe, dass er Erasmus wärmstens verehre. ${ }^{78}$ Innerhalb Polens scheint diese

75 Vgl. ibidem, Nr. 1662, S. 275.63-276.74. Ferner beklagt Erasmus den Zustand von Kirche und Frömmigkeit, der einer Reform bedürfe. Vor diesem Hintergrund sei die Kritik an den Missständen der römischen Kurie und der Tyrannei der Mönche oder der Weltlichkeit mancher Bischöfe durchaus berechtigt, doch sorge er sich über das Aufkommen ,neuer Propheten', namentlich der Anabaptisten. Letztlich aber vertraue er darauf, dass die Entwicklung einen guten Ausgang nehme, schließlich habe Gott auch die Philister, Holofernes oder Nebukadnezzar in seinen Plan einbinden können. Außerdem gebe es neben Luther auch einige Evangelische, die gemäßigt und in ihren Zielen zu unterstützen seien. Auf wen er sich hier bezieht, kann allerdings nicht ausgemacht werden (vgl. ibidem, Nr. 1662, S. 274.27-275.43, 276.78-93, 277.121-127).

${ }^{76}$ Vgl. ibidem, Nr. 1662, S. 276.114-277.117.

77 Vgl. ibidem, Nr. 1753, S. 414-415.

${ }^{78}$ Vgl. ibidem, Nr. 1753, S. 415.26-32: „Aedideram Diatribam, quod intelligerem me non alia ratione liberari posse a tenacissima suspicione quam isti principum animis infixerant; sed disputavi tantum. Lutherus sic respondit ut antehac in neminem virulentius, et homo suavis post aeditum librum per litteras deierat se in me esse animo candidissimo; ac propemodum postulat ut ipsi gratias agam quod me tam civiliter tractarit, longe aliter scripturus si cum hoste fuisset res." Zeitlich zwischen dem Brief an Henckel und diesem an Krzycki sind noch vier weitere Schreiben des Erasmus zu verorten, die für den mittlerweile regen Briefverkehr mit Polen stehen. So gab er Johann Łaski, dem Neffen des Erzbischofs von Gniezno und Primat Polens, der zunächst ein entschiedener Gegner der Reformation und Befürworter der katholischen Reform war, sich ab 1540 aber 
Auseinandersetzung nur noch mehr die gegen Luther gerichtete Haltung zugunsten des Erasmus gestärkt zu haben. So wurde dieser von Leonard Cox, einem aus Wales stammenden Humanisten, der Krzysztof Szydłowiecki zu seinen Patronen zählte und an der Krakauer Universität lehrte, über die polnischen Erasmianer unterrichtet, die sich Erasmus verbunden fühlten und in persönlichem Kontakt miteinander standen. ${ }^{79}$ Namentlich werden Decius, Henckel, Johann Łaski und Andrzej Krzycki genannt. ${ }^{80}$ Wenige Tage nach dessen Brief berichtete Jan Antonin sodann von einem Krakauer Prediger namens Martin Dobergast, der ebenfalls ein glühender Verehrer des Erasmus und zugleich ein entschiedener Luther-Gegner sei. ${ }^{81}$ Dobergast hatte sich 1524 in einer ganzen Predigtreihe kritisch mit Luther auseinandergesetzt und 1526 die gegen den Wittenberger erlassene Bannbulle Papst Leos X. sowie das gegen die Lutherbewegung gerichtete Edikt des polnischen Königs veröffentlicht. ${ }^{82}$ - Vor dem Hintergrund der klaren Positionierung führender Polen in Staat und Kirche zugunsten

den Abendmahlslehren Calvins und Zwinglis öffnete, einen kurzen Bericht über sein Ergehen (vgl. ibidem, Nr. 1674). Am 28. April 1526 sandte Erasmus sodann den ersten Teil seiner Galen-Übersetzung an Jan Antonin (vgl. ibidem, Nr. 1698), ließ Hieronymus Łaski am 9. September gemeinsam mit einem Brief ein Exemplar seiner ,Institutio christiani matrimonii' zukommen (vgl. ibidem, Nr. 1751) und bedankte sich in einem weiteren Schreiben am gleichen Tag bei Krzysztof Szydłowiecki für die gemachten Geschenke (vgl. ibidem, Nr. 1752).

79 Vgl. Allen VII, Nr. 1803, S. 2-5. Zu Leonard Cox vgl. J. Glomski, Patronage and Humanist Literature in the Age of the Jagiellons. Court and Career in the Writings of Rudolf Agricola Junior, Valentin Eck, and Leonard Cox (Toronto, Buffalo und London, 2007); A. Breeze, „Leonard Cox, a Welsh Humanist in Poland and Hungary", Cylchgrawn Llyfrgell Genedlaethol Cymru - The National Library of Wales Journal 25 (1987/88), S. 399-410.

${ }^{80} \mathrm{Vgl}$. Allen VII, Nr. 1803, S. 3.18-28, 43-4.47, 62-65, 72-74. Diesem Brief zeitlich voranzustellen ist noch ein Schreiben des Erasmus an Jakob Piso vom 9. September 1526, in dem er mitteilte, dass sich der Bischof von Olmütz sehr über die ihm gewidmete Plinius-Ausgabe gefreut habe, nun aber auch ein genuin erasmisches Werk wünsche. Aus diesem Grund wurde Piso gebeten, bei Ursinus in Erfahrung zu bringen, welches Thema den Bischof wohl erfreuen könne. Vgl. dazu Allen VI, Nr. 1754.

${ }^{81}$ Vgl. Allen VII, Nr. 1810, S. 29-32, hier: S. 31.77-32.80: „Commendo t. Ampli syncerum virum D. Martinum Dobergast, evangelistam Cracovien $<$ sem $>$, tuorum operum admiratorem, tui nominis magnum praeconem, virum sine dubio doctissimum et vitae integerrimae, in cuius consuetudinem non ita multo ante veni. “ Vgl. auch die Anm. auf S. 31, sowie H. Kowalska, s.v. „Martin Dobergast, documented 1517 - c 1532“, in: Contemporaries of Erasmus 1, S. 394.

${ }^{82} \mathrm{Vgl}$. Allen VII, Nr. 1810, Anm. auf S. 31-32. 
des Erasmus verwundert es nicht, dass das gesamte Jahr 1527 von einem regen Briefverkehr geprägt war, der sowohl die Pflege wie auch den Ausbau der Beziehungen verdeutlicht. ${ }^{83}$ Dabei nahm die Intensivierung des Kontakts genauso zu wie das Bedürfnis, sich über die reformatorische Bewegung auszutauschen: Am 13. August richtete Erasmus ein Schreiben an den Erzbischof von Gniezno, Johann Łaski den Älteren, den Onkel jenes Johann Łaski, mit dem er schon länger in Kontakt stand. ${ }^{84}$ Durch seinen Brief wollte er die Annahme des Erzbischofs entkräften, er unterstütze die Luthersache, denn davon war ihm von dem jüngeren Łaski berichtet worden. ${ }^{85}$ Also widmete er dem Briefempfänger gleich auch seine vierbändige Edition des Kirchenvaters Ambrosius und bot in seinem Schreiben, das sodann als Widmungsvorrede fungierte, einen informativen Überblick über Leben und Werk des Mailänder Bischofs.

Ende Oktober erhielt er von einem gewissen Andrzej Trzecieski ein Schreiben, der ihn um Freundschaft ersuchte. ${ }^{86}$ Trzecieski hatte Hebräisch und Griechisch in Krakau, Leipzig und Erfurt studiert und stand nicht zuletzt durch seinen Kontakt zu Melanchthon der Reformation sehr aufgeschlossen gegenüber. Sein Wohnhaus in Krakau wurde zu einem Treffpunkt religiöser Reformer, doch waren es

83 So wandte sich Erasmus allein im Mai an sieben verschiedene Korrespondenten: Auf Drängen Johann Łaskis (vgl. Allen VI, Nr. 1674) kontaktierte er zunächst Sigismund I., dessen Verdienste er würdigte und dem er eine kurze Abhandlung über Königsherrschaft, Krieg und Frieden zukommen ließ, die noch im gleichen Jahr unter dem Titel ,Desiderii Erasmi Roterodami Epistola ad inclytum Sigismundum regem Poloniae' in Krakau veröffentlicht wurde (vgl. Allen VII, Nr. 1819). Zu diesem Brief vgl. auch P. G. Bietenholz, „Concordia christiana. Erasmus' Thought and the Polish Reality“, Erasmus Studies 21, Nr. 1 (2011), S. 44-70; D. Letocha, „Quand Érasme se fait politique: la première lettre à Sigismond 1er le Vieux“, Renaissance et Réforme 24, Nr. 4 (1988), S. 251-271. Sodann schrieb er an Krzysztof Szydłowiecki, Johann Łaski, Andrzej Krzycki, Leonard Cox, Jan Antonin und Andrzej Zebrzydowski (vgl. Allen VII, Nr. 1820-1822, 1824-1826). Letzterer war ein Neffe Krzyckis und auf Bitten von Leonard Cox (vgl. ibidem, Nr. 1803) hin ermunterte Erasmus den jungen Studenten, sein Studium mit aller Sorgfalt zu verfolgen.

${ }^{84} \mathrm{Vgl}$. Allen VII, Nr. 1855, S. 118-126. Zu dem älteren Johann Łaski vgl. M. Cytowska, s.v. „Jan (I) Łaski, March 1455 - 19 May 1531“, in: Contemporaries of Erasmus 2, S. 296-297; Jürgens, op. cit., S. 22-26.

${ }^{85} \mathrm{Vgl}$. Allen VII, Nr. 1855, S. 120.38-45.

${ }^{86}$ Vgl. ibidem, Nr. 1895, S. 218-220, hier: S. 219.26-220.28. Vgl. auch H. Kowalska, s.v. „Andrzej Trzecieski, d after 20 October 1547“, in: Contemporaries of Erasmus 3, S. 348. 
nicht die kirchenreformerischen Vorstellungen, die ihn zu seinem Schreiben an Erasmus veranlassten, sondern seine humanistischen Interessen. Sein Brief stellt ein wichtiges Zeugnis für die Wahrnehmung des Erasmus im Polen des Jahres 1527 dar. So berichtet Trzecieski einerseits, dass er zugegen war, als Erasmus im Hause von Jan Antonin genauso wie bei Szydłowiecki in höchsten Tönen gelobt wurde. ${ }^{87}$ Andererseits übermittelte er Grüße eines gewissen Johannes Rullus. ${ }^{88}$ Dieser war aus dem Elsass stammend nach Krakau emigriert, hatte dort studiert und wurde in Breslau Schulmeister, gehörte aber weiterhin dem Humanistenzirkel um Leonard Cox an. ${ }^{89}$ Dass Erasmus nicht nur in theologischen Belangen kontaktiert wurde, sondern nun auch - und man mag dies im Vergleich etwa zu französischen, englischen oder deutschen Humanisten als spät bezeichnen für Humanisten in Polen an Bedeutung gewann, bringt nicht nur der Brief Trzecieskis zum Ausdruck. Gegenüber Jan Antonin zählt Erasmus jene Personen auf, die sich kürzlich aus Polen, Schlesien und Ungarn brieflich an ihn gewandt hatten: Paweł Krassowski, der Kanoniker und bischöflicher Generaloffizial in Krakau war; ${ }^{90}$ Jan Zambocki, der Sekretär des Krakauer Bischofs Tomicki; ${ }^{91}$ Georg Werner, ein Schlesier, der in Ungarn lebte und dessen Gedichte gelegentlich gemeinsam mit den Briefen des Erasmus an Sigismund I. von Hosius publiziert wurden; ${ }^{92}$ Johann Lange von Karvinà, der zu dieser Zeit Schulmeister im schlesischen Złotoryja war, sich später aber am Hofe Ferdinands von Habsburg befand. ${ }^{93}$ Über ihre Kontaktaufnahmen

${ }^{87}$ Vgl. Allen VII, Nr. 1895, S. 219.5-11.

88 Johannes Rullus stammte aus dem Elsass, schloss sich aber nach dem Studium in Krakau und Wien dem Humanistenzirkel um Leonard Cox an. Vgl. dazu H. Kowalska, s.v. "Johannes Rullus of Cracow, d June 1532“, in: Contemporaries of Erasmus 3, S. 178.

${ }^{89} \mathrm{Vgl}$. Allen VII, Nr. 1895, S. 220.35-36 sowie die Anm. dort.

${ }^{90}$ Vgl. H. Kowalska, s.v. „Paweł Sebastian Krassowski, d 2 October 1545“, in: Contemporaries of Erasmus 2, S. 273.

91 Zu Zambocki vgl. H. Kowalska, s.v. „Jan Zambocki, d 24 March 1529“, in: Contemporaries of Erasmus 3, S. 467-468.

${ }^{2} \mathrm{Zu}$ Werner vgl. H. Kowalska, s.v. „Georg Werner of Paczkow, died c 1557“, in: Contemporaries of Erasmus 3, S. 438-439. Zu Stanislaus Hosius vgl. H. Kowalska, s.v. „Stanislaus Hosius of Cracow, 5 May 1505 - 5 August 1579“, Contemporaries of Erasmus 2, S. 206-207.

93 Vgl. Allen VII, Nr. 1916, S. 269-271, hier: S. 269.19-271.24 sowie die dortigen Anm. Dem Brief zeitlich voranzustellen ist noch ein Schreiben an Johann Łaski (vgl. ibidem, Nr. 1915). Zu Johann Lange vgl. M. Erbe, s.v. „Johann Lange of Karvinà, 16 April 1503 - 25 September 1567“, in: Contemporaries of Erasmus 2, S. 290. 
hatte sich Erasmus offensichtlich sehr gefreut und er nannte sie namentlich, da Łaski einige zu ihren Briefen ermuntert hatte. Ihre Namen stehen repräsentativ für die wachsende Bedeutung, die Erasmus unter den hiesigen Gelehrten und Amtsträgern einnahm. Während sich die früheren Kontakte auf die geistliche und weltliche Elite Polens mit einer Handvoll Humanisten konzentriert hatten, ${ }^{94}$ interessierte sich nun auch die zweite und dritte Reihe von Gelehrten für ihn. Man wird dies vor allem auf die Veröffentlichungen und die Rezeption erasmischen Schrifttums zurückführen und die Entwicklung mit jener in anderen europäischen Ländern vergleichen dürfen, die sich in West- und Südeuropa schon zehn Jahre zuvor u.a. aufgrund der physischen Präsenz des Erasmus ereignet hatte.

Seit Dezember 1527 wurde die reformatorische Bewegung in Deutschland im Briefwechsel zunehmend von polnischer Seite thematisiert und blieb das gesamte Folgejahr bestimmend. Der aus dem schlesischen Schweidnitz stammende Caspar Ursinus, der vorübergehend in Basel gewohnt hatte, war nun nach Wien umgezogen, um den Unruhen zu entfliehen, die überall in Deutschland von den Evangelischen hervorgerufen wurden. ${ }^{95}$ Wie auch die große Mehrheit der in Polen lebenden Korrespondenten des Erasmus lehnte er nicht nur die Vorgehensweise, sondern auch die Ziele der Reformatoren ab. Es scheint fast, als schätzte er, der gerade nach Wien gezogen war, die drohende Türkengefahr als geringer ein. An Erasmus gerichtet, brachte er seine Überzeugung zum Ausdruck, dass die Türken, wenn sie erst von der evangelischen Bewegung gehört hätten, Deutschland erst recht angriffen - aber nicht, weil es aufgrund der Unruhe nun leichter zu überwältigen sei, sondern um eine weitere Ausbreitung der Reformation zu verhindern. ${ }^{96}$ Wenngleich Ursinus

${ }^{94}$ Vgl. dazu auch Louthan, op. cit., S. 20-27.

95 Vgl. Allen VII, Nr. 1917, S. 271-273, hier: S. 272.34-41: „Ad me et privata hec studia redeo, qui adhuc in veteri sententia permaneo, propter violentes ac furiosos Euangelii interpretes qui passim in Germania exorti sunt, quique horribiles tumultus exciverunt, ubivis gentium quam in ista natione, homini pie recteque instituto, hac tempestate vivendum esse. Quapropter Basilaea Viennam reversus, comparato viatico ac sumptu in unum alterumque annum, in Italiam me recoepi." Dem Brief des Ursinus folgt in der Edition ein Brief des Erasmus an Krzysztof Szydłowiecki (vgl. ibidem, Nr. 1918).

96 Vgl. ibidem, Nr. 1917, S. 273.51-59: „Porro quae in intima Germania iam insedit, et regnum inter partim improvidos, partim impios, et malignos possidet, eam credo suis ipsius viribus propediem corruituram, relicturamque nationi praeter caedes ac foedissimas dissensiones et resuscitatam immanissimam 
hier sicher etwas übertrieb, entsprach seine Wahrnehmung der reformatorischen Bewegung als Bedrohung dem Stereotyp in Polen. In seinem Brief an Erasmus lobte Sigismund I. diesen nämlich für seine wahre, christliche Gesinnung und betonte zugleich, alles daran zu setzen, in Polen eine änliche Ausbreitung der „lutherischen Seuche“ zu verhindern und den gegenwärtigen Zustand zu bewahren. ${ }^{97}$ An diesem Schreiben wird die verstärkte thematische Auseinandersetzung mit der Reformation genauso deutlich wie die sich noch steigernde Hochachtung gegenüber Erasmus, denn Sigismund lud ihn bei dieser Gelegenheit nicht nur nach Polen ein, sondern ließ ihm auch hundert Golddukaten zukommen. ${ }^{98}$ Ähnliches bringen die beiden auf den folgenden Tag datierten Briefe zum Ausdruck, die vermutlich mit dem gleichen Boten Erasmus überbracht wurden, da der polnische Reichstag zu dieser Zeit in Piotrków tagte. Während sich Tomicki in dem einen Schreiben für das Freundschaftsangebot des Erasmus bedankte und ihm sechzig ungarische Dukaten schenkte, ${ }^{99}$ gab Johann Łaski in dem anderen einen kurzen Bericht des Reichstages. ${ }^{100}$ Demnach habe sich sein Onkel, der gerade den Vorsitz des Senats führe, sehr über die Ambrosius-Ausgabe des Erasmus gefreut. Von vielen habe er gehört, dass sie auf sein Werk von der Predigtkunst genauso wie auf seine Augustinus-Edition warteten. ${ }^{101}$ Vor diesem Hintergrund scheint daher wahrscheinlich, dass das Oeuvre des Erasmus gelegentlich Gesprächsthema in den Sitzungspausen des polnischen Reichstages war. Doch auch in diesem Schreiben wurde die Reformation

barbariem, dedecus apud exteras nationes sempiternum et odium inexpiabile. Credo quidem, si Turca rescierit tam nefarios hominum perditissimorum ausus, si non praedae cupidine, at ne virus hoc in suae ditionis loca pervadat, Germaniam ultro venturum oppugnatum."

97 Vgl. ibidem, Nr. 1952, S. 331-332, hier: S. 331.12-16, 18-21: „Nam etsi nobis maxime cordi est ut et rempublicam Christianam adeo inclinatam pro virili nostra iuvemus, et regna nostra tranquilla, quoad fieri potest, atque ab illa plusquam Lutherana lue qua nunc sursum ac deorsum fertur Germania, incontaminata servemus; [- - Immo eciam hoc ardencioribus votis Domini misericordiam imploramus, ut quemadmodum nos regnaque nostra hactenus integra illesaque servavit, ita adhuc servet imposterum, quousque illius visum fuerit voluntati.“

98 Vgl. ibidem, Nr. 1952, S. 331.27-332.36. Die Summe von hundert ungarischen Golddukaten wurde Erasmus von Andrzej Zebrzydowski gemeinsam mit einem Schreiben von Justus Decius überbracht (vgl. ibidem, Nr. 1958).

${ }^{99}$ Vgl. ibidem, Nr. 1953, S. 333.

100 Vgl. ibidem, Nr. 1954, S. 333-334.

101 Vgl. ibidem, Nr. 1954, S. 333.20-22, 334.58-59. 
wieder zum Thema gemacht, wenn Johann Łaski den Rotterdamer dazu aufruft, gemeinsam alles dafür zu tun, dass die Lutheraner in Polen nicht Fuß fassen können. ${ }^{102}$ Es entsteht somit der Eindruck, dass der quantitative Anstieg der Briefe in diesen Jahren nicht allein auf die Verbreitung und die Rezeption erasmischer Texte in Polen zurückzuführen ist. Natürlich hatte dies Erasmus mittlerweile auch in Polen zu einer geistigen Galeonsfigur werden lassen, doch hoffte man angesichts der wachsenden Bedrohung, die vom Nachbarland ausging, darauf, in ihm einen Verbündeten in der Abwehr der Evangelischen zu gewinnen. Diese Hoffnung war sicher durch die Auseinandersetzung mit Luther in der Frage der menschlichen Willensfreiheit noch genährt worden, da sich Erasmus nun auch öffentlich zunehmend von diesem distanzierte. Außerdem folgte er dem Aufruf Johann Łaskis und bezog zunächst in Briefen Stellung zur Luthersache. Dabei wandte er sich am 27. August 1528 zunächst an den polnischen Kanzler Krzysztof Szydłowiecki, den er zwar ermutigte, den eingeschlagenen Kurs beizubehalten, zugleich aber seine Überzeugung zum Ausdruck brachte, dass es angesichts der Zustände in Kirche und Gesellschaft vorrangig Aufgabe von Bischöfen und weltlichen Fürsten sei, eine Verbesserung anzustreben. ${ }^{103}$ Ähnlich äußerte er sich am folgenden Tag gegenüber Sigismund I., dessen clementia er lobte und den er wissen ließ, dass er täglich Gott darum bitte, er möge alle Fürsten mit gleichen Gaben ausstatten. ${ }^{104}$ Wiederum drei Tage später schrieb er an Tomicki, den er als Zierde der Kirche bezeichnete und sich mehr Bischöfe seiner Art wünschte. ${ }^{105}$

Bis Ende des Jahres 1528 avancierte Erasmus in Polen zu einer gefeierten Autorität, seine Texte wurden nicht mehr nur in Humanistenzirkeln gelesen. Die Briefe, die ihm vom polnischen Reichstag gemeinsam mit Münzgeschenken ausgestellt wurden, markieren den vorläufigen Höhepunkt der Erasmus-Verehrung in Polen. Auch

${ }^{102}$ Vgl. ibidem, Nr. 1954, S. 334.35-48, bes. 41-43: „Cavemusque diligentissime ne quid hic proficiat Lutherus aut ipsius factio, neve e diverso regnent illi quibus id quicquid usquam est malorum, totum debemus."

${ }^{103}$ Vgl. ibidem, Nr. 2032, S. 452-453, hier: S. 452.20-453.25. In der Edition finden sich zuvor noch Briefe an Caspar Ursinus, Andrzej Krzycki und Justus Decius (vgl. ibidem, Nr. 2008, 2030-2031). Decius berichtet er genauso wie im nächsten Brief an Johann Łaski davon, dass er mit Zebrzydowski, der ihm die Dukaten des Königs überbracht hatte, nun seinen Haushalt in Basel teile (vgl. ibidem, Nr. 2031, S. 451-452, hier: S. 452.24-25; Nr. 2033, S. 453-456, hier: S. 453.1-4). ${ }^{104}$ Vgl. ibidem, Nr. 2034, S. 456-458, bes. S. 457.44-66, 458.78-80.

105 Vgl. ibidem, Nr. 2035, S. 458-459, hier: S. 458.17-18. 
insgesamt bezeugt die Korrespondenz, dass er nicht nur als Humanistenfürst kontaktiert wurde, sondern als eine intellektuelle Autorität, deren öffentliche Bedeutung in Polen stetig zunahm. Wohl auch aus diesem Grund suchte man zu ihm den Kontakt, da man sich in ihm einen starken und wortgewaltigen Verbündeten erhoffte, der dabei behilflich sein konnte, die Ausbreitung der reformatorischen Bewegung über die Reichsgrenzen hinaus nach Polen zu verhindern. Wie die im dortigen Königreich lebenden Korrespondenten in ihren Briefen verdeutlichten, wurden die Evangelischen als größte Gefahr angesehen, der man sich mit aller erdenklichen Gegenwehr entgegenstellen musste. Schon rasch hatte sich bei ihnen die anfängliche Geringschätzung über Verachtung in eine Wahrnehmung der Bedrohung verwandelt. Erasmus, der lange unentschlossen blieb, distanzierte sich spätestens in Folge des Streits mit Luther auch von der reformatorischen Bewegung. Gegen Ende 1528 sind auch in seinen Briefen erste Anzeichen einer Gegenwehr festzustellen.

\section{Die Jahre von 1529 bis August 1532:}

Furcht und Hilflosigkeit

In gewisser Weise bezog Erasmus Stellung zum reformatorischen Geschehen, als er Basel verließ und der Einladung König Ferdinands folgte, sich in Freiburg niederzulassen. Auch wenn er Piotr Tomicki schrieb, dass der Grund seines Umzugs darin zu sehen sei, dass es im Breisgau ruhiger sei, hatte dies doch auch nach außen Symbolkraft. ${ }^{106}$ Trotzdem sah er die reformatorischen Ziele weiterhin differenziert und musste gegenüber Justus Decius einräumen, dass manche Positionen Luthers in der menschlichen Willensfrage richtig seien und den Aussagen des Evangeliums sehr nahe kämen. ${ }^{107}$ Er gab sich sogar weiterhin gesprächsbereit, da er es als gewinnbringend ansah, über die

106 Vgl. Allen VIII, Nr. 2173, S. 187-189, hier: S. 188.24-32. Dieser Brief, der wie Nr. 2174 (an Andrzej Krzycki) und Nr. 2175 (an Justus Decius) auf den 8. Juni 1529 datiert ist, stellt die Antwort auf ein Schreiben dar, das Tomicki am 20. April 1528 an Erasmus adressiert hatte, das heute aber verloren ist. Ebenso hatte Erasmus bereits im Frühjahr an Krzycki geschrieben, aber auch dieser Brief gilt als verschollen. Bereits im Januar hatte Erasmus einen Brief an Tomicki gerichtet (Nr. 2091), der zugleich als Dedikationsepistel der zweiten Ausgabe seiner Seneca-Edition vorangestellt wurde.

107 Vgl. ibidem, Nr. 2175, S. 190-191, hier: S. 190.5-6, 10-11: „Quae Lutherus destomachatur in nostros, veriora sunt quam vellem. [- - Et quae Lutherus urget, si moderate tractentur, mea sententia propius accedunt ad vigorem Evangelicum." 
Willensfreiheit, den Wert guter Werke oder menschliche Verdienste zu diskutieren. Was er hingegen ablehnte, war Luthers impulsive Gesprächsführung, die aus seiner Sicht oft von Dogmen und Animositäten geprägt war. ${ }^{108}$ Den unter den Reformatoren geführten Streit um das rechte Abendmahlsverständnis konnte er indes nicht recht nachvollziehen - schließlich, so Erasmus, werde die göttliche Natur angebetet, die sowieso stets gegenwärtig sei. Zudem könne er keine einzige Bibelstelle ausmachen, die davon berichtet, die Apostel hätten Brot und Wein zu Fleisch und Blut Christi konsekriert. Daher bleibe er weiterhin beim Abendmahlsverständnis der römischen Kirche und wisse sich darin mit Decius verbunden. ${ }^{109}$

Da Erasmus im Juni und Juli 1529 erneut seinen Umzug nach Freiburg zum Thema machte und obendrein die Frömmigkeit König Ferdinands lobend hervorhob, ${ }^{110}$ scheinen doch auch andere Gründe für seinen Ortswechsel vorgelegen zu haben als bloß die ruhigere Atmosphäre. Tatsächlich ist der konkrete Anlass bei genauerer Betrachtung in der Entwicklung zu sehen, die sich in evangelischen oder zumindest der Reformation offen gegenüberstehenden Territorien abspielte. Am Beispiel Basels scheint er die Verhältnisse mit jener aufbrausenden, aggressiven Art vergleichen zu wollen, die ihn an Luther störte und von der er gerade Decius berichtet hatte. Er brachte dies wiederholt an Beispielen zum Ausdruck, die sich im Winter 1528/29 abgespielt hatten, als bewaffnete Banden hasserfüllt durch die Stadt gezogen seien, um Altäre, Statuen und Bilder zu zerstören. ${ }^{111}$ So wie er zu Luther auf Abstand gegangen war, distanzierte er sich jetzt auch räumlich von Basel. Doch beschränkten sich die geschilderten Ereignisse nicht auf eine Stadt - gegenüber Krzycki berichtete Erasmus, dass in ganz Deutschland eine Stimmung zu beobachten sei, die ständig zwischen Hoffnung und Furcht abwechsle. ${ }^{112}$ Aus diesem Grund wünsche er sich oft nach Krakau, doch lasse sein Gesundheitszustand

${ }^{108}$ Vgl. ibidem, Nr. 2175, S. 190.6-9, 11-13: „De libero arbitrio, de bonis operibus ac meritis, deque similibus, themata sunt quae cum fructu pietatis disputari possent inter eruditos, si absit pervicacia veritatis inimica et odium excaecans omne iudicium. [- ] Quod in imagines odiose saevitum est, minimum faciebat ad pietatem, ad seditionem plurimum."

${ }^{109}$ Vgl. ibidem, Nr. 2175, S. 190.13-191.27.

${ }^{110}$ Vgl. ibidem, Nr. 2176 (an Jan Antonin; vgl. bes. S. 192.65-69), Nr. 2177 (an Krzysztof Szydłowiecki; vgl. bes. S. 193.40), Nr. 2201 (an Andrzej Krzycki).

111 Vgl. ibidem, Nr. 2201, S. 244-247; hier: S. 245.34-44.

112 Vgl. ibidem, Nr. 2201, S. 246.77-78. 
dies nicht zu. Mit einem Augenzwinkern fügte er hinzu, dass ihn ja vielleicht ein Engel dorthin bringe wie einst Habakuk nach Babylon. ${ }^{113}$ Während er offensichtlich nicht in der Verfassung war, die Reise nach Polen auf sich zu nehmen, kamen immer wieder Polen zu ihm. Andrzej Zebrzydowski, der ein Neffe Krzyckis war, hatte ihn nun nach längerem Aufenthalt verlassen, ${ }^{114}$ doch war dessen Begleiter Marcin Słap Dąbrowski weiterhin Gast in seinem Hause. ${ }^{15}$ Erst im folgenden Jahr reiste auch er wieder in die Heimat zurück. Aus einer Adelsfamilie aus Dambrowska bei Posen stammend, war er 1528 Klient Krzyckis geworden. Im Juli 1530, nachdem er wieder in Polen eingetroffen war, berichtete er Erasmus davon, dass er sein Land als ein Unbekannter verlassen habe, nun aber mit Beifall wieder empfangen worden sei. Die Erklärung war für ihn einzig darin zu sehen, dass er so lange den engen Kontakt zum Rotterdamer hatte genießen dürfen. ${ }^{116}$ Wenngleich sein Bericht über die Heimkehr sicher stilisiert ist, gibt er dennoch Zeugnis von dem hohen Ansehen, in dem Erasmus in Polen stand. Gleichermaßen wurde er hier als Humanist und Theologe geschätzt, allerdings scheint es für viele Polen wichtiger gewesen zu sein, dass er sich gegen Luther positionierte als dass

113 Vgl. ibidem, Nr. 2201, S. 246.78-81: „Quoties optavimus subito esse Cracoviae! se sic delati quemadmodum ő $\gamma \gamma \varepsilon \lambda \mathrm{o} \varsigma$ capillo detulit Abacuk Babylonem ad Danielem, aut quemadmodum Mercurius Menippum e coelo deportavit Athenas."

${ }^{114}$ Vgl. Allen VII, Nr. 2031, 2033. Zu Zebrzydowski vgl. H. Kowalska, s.v. „Andrzej Zebrzydowski, d 23 May 1560“, in: Contemporaries of Erasmus 3, S. 473-474.

115 Vgl. Allen VIII, Nr. 2201, hier: S. 246.58-60: „Pro Zebridovio, quo diutius frui non licuit, adest Martinus Dambroviskius, quem tu rectissimo consilio nepoti tuo convictorem dederas.“ Vgl. auch H. Kowalska, s.v. „Martin Słap Dąbrowski, d before 19 November 1550“, in: Contemporaries of Erasmus 3, S. 258-259.

${ }^{116}$ Vgl. Allen VIII, Nr. 2351, S. 480-483, hier: S. 481.33-38: „Sed proferramne ego et alias laudes, quibus nuper tam ornatus et tam gratus in Poloniam veni? proferrem sane, ne gloriose magis quam necessario facere viderer. Nam qui prius vix uni matri cognitus domum redibam, nunc tanto applausu omnium, ignotissimorum quoque, honorificentissime exceptus eram, in tantum ut nunquam in patria fuisse mihi visus sim, nisi quando redieram ab Erasmo." Nach seiner Rückkehr machte Dąbrowski Karriere als kirchlicher Verwalter in der Diözese Posen. Zeitlich diesem Brief voranzustellen ist noch ein Schreiben von Caspar Ursinus aus Linz, datiert auf den 20. April 1530, das auf ein verlorenes Schreiben des Erasmus antwortet (vgl. ibidem, Nr. 2313). 
er in allem der Papstkirche folgte. Denn dass er nicht nur hinsichtlich reformatorischer Ansichten differenzierte, sondern genauso in Bezug auf kirchliche Dogmen - und seine Ansichten in dieser Hinsicht offen zum Ausdruck brachte - wird in einem Brief an Krzysztof Szydłowiecki vom 2. September 1530 deutlich. ${ }^{117}$ Vor dem Hintergrund des Speyerer Reichstages 1529 und den Ergebnissen des Augsburger Reichstages von 1530, in dessen Verlauf auf das Augsburger Bekenntnis hin von Kaiser Karl V. die katholische Widerlegung verlesen und die überarbeitete Apologie sogar abgelehnt worden war, wird nachvollziehbar, wieso Erasmus zum Schluss kam, der Kaiser wolle nur eine einzige Konfession, wobei er in allen Fragen den päpstlichen Weisungen Folge leiste. Erasmus räumte in diesem Zusammenhang ein, dass dies ja prinzipiell erfreulich wäre, wenn der Papst nur allein Weisungen erließe, die auch im Sinne Christi seien. ${ }^{118}$ Daran wird deutlich, wie verfahren die Situation im Reich war und wie viele Parteien mit ganz unterschiedlichen Interessen dafür sorgten, dass die Probleme nicht gelöst werden konnten. Dabei stellten für Erasmus die im Zuge dieser Entwicklung überall aufkommenden häretischen Gruppen noch vor Bauernkrieg, sonstigen Übeln und Türkengefahr die größte Bedrohung für das Reich dar. ${ }^{119}$ Angesichts der in früheren Beispielen diagnostizierten Furcht vieler polnischer Korrespondenten, die reformatorische Bewegung könne sich auch in ihrer Heimat ausbreiten, verwundert es, dass auf die hier von Erasmus vorgenommenen Situationsberichte nicht entsprechende Reaktionen kamen. Dass dies allein auf einen möglichen Verlust entsprechender Briefe zurückzuführen ist, scheint nicht sehr wahrscheinlich, da bis Anfang August 1532 immerhin achtzehn Briefe nachweisbar sind, von denen allein zehn von den in Polen lebenden Korrespondenten verfasst

117 Vgl. Allen IX, Nr. 2376, S. 28-29.

118 Vgl. ibidem, Nr. 2376, S. 28.19-29.21: „Caesar, ut est singulari religione praeditus, videtur omnia gesturus ex praescripto Pontificis. Res salva est, si nihil praescribet Pontifex nisi quod Christo gratum est." Ähnliches, aber in abgeschwächter Form schrieb er einen Tag zuvor an Andrzej Krzycki (vgl. ibidem, Nr. 2375, S. 25-28, hier: S. 26.43-46).

${ }^{119}$ Vgl. ibidem, Nr. 2375, S. 28.106-112: „Quid a Turca passa sit Hungaria et Austria notum est omnibus; quid passura sit incertum. Quid nunc commemorem furiosos agricolarum tumultus? Quid tot morborum ac pestium nomina, imo novas et nondum nomen sortitas species? Quid rerum ad usum vitae necessariarum tantam vel inopiam vel charitatem? Quanquam haud scio an inter haec mala primus locus debebatur haereseon dissidiis." 
wurden. ${ }^{120}$ Da sich darunter auch Schriftstücke von Personen befinden, die mit Erasmus neu in Kontakt traten, wird zum einen seine anhaltende Bedeutung für viele Polen unterstrichen, zum anderen der Verlust von Briefen bedeutender und langjähriger Korrespondenten umso unwahrscheinlicher. Dennoch ist erstaunlich, dass nur im Brief von Johann Benedicti vom 4. Februar 1532 die Ereignisse um die reformatorische Bewegung zum Thema gemacht werden - dafür hier umso deutlicher. ${ }^{121}$ Benedicti, der im schlesischen Glogau um 1490 geboren wurde, war Kanoniker in Krakau, Breslau und Vilnius, bevor er als Leibarzt in die Dienste Sigismunds I. trat. Bei diesem muss er sich ein sehr hohes Ansehen erworben haben, da ihm nicht nur die Adelsrechte, die ihm der römisch-deutsche Kaiser verliehen hatte, bestätigt wurden, sondern er als einziger Nichtpole kirchliche Pfründen haben durfte. ${ }^{122}$ Wie sein Brief zudem deutlich macht, war er ein überaus papsttreuer Katholik. So verlieh er gleich seiner Überzeugung Ausdruck, die Evangelischen gingen samt ihrer Lehre geradewegs in die Hölle. ${ }^{123}$ Mit drei Argumenten suchte er, dies zu untermauern: Zunächst verfügten sie seiner Meinung nach nicht über den Heiligen Geist, da dieser sich durch Frieden auszeichne, sie aber alles andere als Frieden brächten. Sodann würden die Menschen durch ihre irdische, den Überzeugungen der Apostel widersprechende Lehre genauso versucht wie einst Jesus durch den Teufel (Mt 4). Zuletzt lehnten sie die Vorstellung des Fegefeuers ab, da es keine biblischen Belegstellen gebe. Dabei müssten sie durch ihr Bibelstudium doch wissen, dass

${ }^{120}$ Erasmus adressierte Briefe an folgende Personen: Piotr Tomicki (Allen IX, Nr. 2377), Caspar Ursinus (ibidem, Nr. 2453 und 2517), Severin Boner (ibidem, Nr. 2533), Johann Boner (ibidem, Nr. 2549), zugleich an Johann und Stanislaus Boner (ibidem, Nr. 2584), an Piotr Tomicki (ibidem, Nr. 2600) sowie Johannes Dantiscus (Allen X, Nr. 2643). Im gleichen Zeitraum erhielt er Briefe von König Sigismund I. (Allen IX, Nr. 2520), Piotr Tomicki (ibidem, Nr. 2521), Stanislaus Aichler (ibidem, Nr. 2545), Johann Boner (ibidem, Nr. 2548, 2550 und Allen X, Nr. 2658), Johann Benedicti (Allen IX, Nr. 2601), Anselm Ephorinus (ibidem, Nr. 2606) sowie Caspar Ursinus (Allen X, Nr. 2664) und Stanislaus Turzo (ibidem, Nr. 2699).

121 Vgl. Allen IX, Nr. 2601, S. 420-424.

122 Vgl. ibidem, Nr. 2601, S. 420. Vgl. zu ihm auch H. Kowalska, s.v. „Jan Benedykt Solfa of Trzebiel, 1483 - 31 March 1564“, in: Contemporaries of Erasmus 3, S. 264-265.

${ }^{123}$ Vgl. Allen IX, Nr. 2601, S. 421.21-23: „Multe tum sunt vie, que videntur hominibus recte, et novissima eorum proveniunt ad profunda inferni.“ 
die Apostel Regeln verkünden dürften, die sie ihrerseits von Gott erhalten hätten $\left(1\right.$ Kor 11,23). ${ }^{124}$ Ein Trost, so schloss Benedicti, sei ihm nur, dass der Jüngste Tag gewiss sei und weder Hiob noch David oder Noah den Evangelischen dann noch helfen könnten. ${ }^{125}$ - Die sprachliche Gestalt seines Briefes zeugt davon, dass Benedicti sicher einer der schärfsten Luthergegner in Polen war. Seine Position am Hofe sowie die mitgedachte Möglichkeit, der Brief könnte in falsche Hände geraten oder publiziert werden, lassen erwarten, dass er abseits aller Polemik die Mehrheitsmeinung in Polen zum Ausdruck brachte. Andernfalls wäre seine aggressive Ablehnung sicher nicht in dieser Form toleriert worden, ganz gleich welche Gunst er am Hofe genoss. Insofern steht die hier zum Ausdruck kommende grundsätzliche Ablehnung jeglicher Reformbestrebungen in Kirche und Glauben in Kontinuität zu der mit früheren Beispielen zu belegenden Stimmung in Polen und kann leicht das Ausbleiben sonstiger Stellungnahmen zur Reformation im Jahr 1531 wettmachen. Dass er sich mit diesen offenen Worten an Erasmus wandte, veranschaulicht einmal mehr die ebenfalls konstant gebliebene Wertschätzung von Seiten der in Polen lebenden Korrespondenten.

Das weiterhin hohe Ansehen wird ferner auch an Briefen von jenen Personen deutlich, die bislang noch nicht mit Erasmus in Kontakt gestanden hatten: Aus Krakau wandte sich Sigismund I. am 17. August 1531 mit der Bitte an den Rotterdamer, den Sohn des örtlichen Burggrafen Severin Boner zu unterrichten. ${ }^{126}$ Am gleichen Tag - und daher sicher mit dem gleichen Boten übermittelt

${ }^{124}$ Vgl. ibidem, Nr. 2601, S. 422.44-48, 63-66: „In Lutheranis ergo non est spiritus sanctifficationis aut Spiritus Sanctus, qui est spiritus mansuetudinis et apostolis sub specie columbae apparuit, qui non est autor conffusionis, sed pacis, ut in omnibus congregacionibus sanctorum. [- - Interpretantur scripturam, sicut dyabolus interpretabatur Mathei iiii, ut est videre in mille et aliquot locis scripture primo sermone falso depromptis." Vgl. ibidem, S. 423.90-94: „nec credunt purgatorium, dicentes neutiquam scripturam hoc expressisse, scientes non omnia scripta esse in hoc libro, sed aliqua per apostolos, ad Corinthios scribente Paulo, ordinata, dicente ,Ego enim, quod accepi a Domino, hoc tradidi vobis. Cetera autem, cum venero, disponam'."

125 Vgl. ibidem, Nr. 2601, S. 424.136-137: „Cum autem ad tribunal Christi venerimus, nec Iob, nec Daniel, nec Noe rogare possunt pro quoquam.“

126 Vgl. ibidem, Nr. 2520, S. 316-317, hier: S. 317.1-8. Sigismund I. und Erasmus hatten bereits zuvor Briefe gewechselt (vgl. Allen IV, Nr. 1819, 1952), durch das hiesige Schreiben wurde nun aber auch Severin Boner zu einem Briefpartner des Rotterdamers. 
- verfasste auch Piotr Tomicki ein Schreiben, in dem er einleitend betonte, keinen berühmteren Freund als Erasmus zu haben, um sich sodann auf Bitten Severin Boners bei ihm einzusetzen. ${ }^{127}$ Dass sich in dieser Angelegenheit sowohl der polnische König als auch der Krakauer Erzbischof, der als entschiedener Luthergegner galt, an Erasmus wandten, unterstreicht die gemachten Beobachtungen hinsichtlich der polnischen Erasmus-Verehrung. Daneben wird am Beispiel Boners aber auch ersichtlich, dass die Vertreter dieser Verehrung in engem Kontakt miteinander standen und zwischen zahlreichen, in Polen lebenden Korrespondenten auch familiäre Bande bestanden. Dies wird neben etwa den Mitgliedern der Familie Łaski, die schon in frühesten Zeiten zu Briefpartnern des Erasmus geworden waren, neben Andrzej Zebrzydowski, ein Neffe Andrzej Krzyckis, der seinerseits wiederum Piotr Tomicki zum Onkel hatte, auch deutlich am Beispiel der Boners. Severin Boner (1487-1549) stammte aus Landau im Elsass, war aber seinem Onkel Johann nach Polen gefolgt, der bereits zuvor dorthin emigriert war. ${ }^{128}$ Neben seiner späteren Tätigkeit als Krakauer Burggraf verwaltete Severin auch die Salzminen von Wieliczka. Aus seiner ersten Ehe entstammte Johann, den er nun Erasmus zur Ausbildung zu überantworten wünschte, sowie Stanislaus. ${ }^{129}$ In zweiter Ehe war er mit der Nichte von Johann Łaski, dem Reformer, verheiratet. ${ }^{130}$ Mit Severin und seinen beiden Söhnen entwickelte sich ein reger Briefverkehr, ${ }^{131}$ den Erasmus zwei Wochen nach den Bitten von Sigismund und Tomicki durch persönliches Schreiben an Severin Boner eröffnete. ${ }^{132}$ Selbstverständlich lud er Johann Boner zu sich ein, der sodann gemeinsam mit seinem Begleiter Stanislaus Aychler

${ }^{127}$ Vgl. Allen IX, Nr. 2521, S. 317-318, hier: S. 317.4-5: „amicum enim tam insigni laude et cumulata virtute preter te habeo neminem." Vgl. daneben ibidem, S. 317.9-318.23.

${ }^{128} \mathrm{Vgl}$. dazu die Vorbemerkung zu ibidem, Nr. 2533, S. 336-340, hier: S. 336-337. Zu Severin Boner vgl. H. Kowalska, s.v. „Seweryn Boner of Cracow, 1466 - 12 May 1549“, in: Contemporaries of Erasmus 1, S. 167-168.

$129 \mathrm{Zu}$ den Söhnen Severin Boners vgl. eadem, s.v. „Jan Boner of Cracow, 1516 - 12 September 1562", in: Contemporaries of Erasmus 1, S. 166-167; eadem, s.v. „Stanisław Boner of Cracow, c 1523 - 14 November 1560“, in: Contemporaries of Erasmus 1, S. 168.

${ }^{130}$ Vgl. dazu die Vorbemerkung zu Allen IX, Nr. 2533, S. 336-340, hier: S. 336-337.

131 Vgl. dazu ibidem, Nr. 2548-2550, 2584 sowie Allen X, Nr. 2658, 2717 und Allen XI, Nr. 3010.

${ }^{132}$ Vgl. Allen IX, Nr. 2533, hier: S. 336-337. 
(oder latinisiert: Glandinus) ${ }^{133}$ fünf Monate bei ihm lebte, nachdem sie mit Anselm Ephorinus ${ }^{134}$ eine Studienreise durch Deutschland und Italien unternommen hatten. Auch widmete Erasmus den beiden Söhnen Severin Boners das Vorwort zu seiner Terenz-Ausgabe. ${ }^{135}$ Erasmus war auch seinerseits an der Gewinnung neuer Kontakte interessiert. So ist ein Brief an Johannes Dantiscus, den Bischof von Kulm, nachweisbar, der zugleich als Vorwort zur Übersetzung von ,De Spiritu Sancto' des Basilius diente. ${ }^{136}$

In gewisser Weise war die anhaltende Verehrung von Seiten der polnischen Bekannten sicher eine Ermutigung für Erasmus, da er in der gleichen Zeit vor allem in Spanien und Frankreich heftig kritisiert wurde und hier gelegentlich noch im Verdacht stand, mit den Evangelischen zu sympathisieren. ${ }^{137}$ Für seine polnischen oder im dortigen Königreich lebenden Korrespondenten scheinen diese Unterstellungen in keiner Weise in Frage zu kommen. Dennoch darf nicht geschlussfolgert werden, aufgrund des langen Schweigens in der Korrespondenz habe das reformatorische Geschehen keine Rolle mehr gespielt. In dieser Hinsicht ist der Zeitraum von 1529 bis August 1532 vielmehr von Furcht und Hilflosigkeit gekennzeichnet gewesen. So wie Erasmus sich vor Übergriffen in Basel gefürchtet hatte und sich keinen anderen Rat mehr wusste, als die Stadt zu verlassen, so steht das Schreiben des erzürnten Johann Benedicti stellvertretend für die Hilf- und Ratlosigkeit, den Evangelischen Wirkungsvolles entgegenzusetzen, sollte sich in Polen

133 Über die Herkunft des Stanislaus Glandinus ist wenig bekannt. Er war um 1517 geboren worden, sein Vater scheint in Krakau gelebt zu haben. Spätestens 1535 erwarb er einen juristischen Doktorgrad und arbeitete als Notar in Krakau. Er heiratete die Tochter des Justus Decius. Vgl. dazu das Schreiben des Erasmus an Glandinus vom 19. September 1531 bei Allen IX, Nr. 2545, S. 352-353. Daneben ist nur noch ein Schreiben des Glandinus an Erasmus überliefert (vgl. Allen X, Nr. 2718). Vgl. auch H. Kowalska, s.v. „Stanisław Aichler of Cracow, c 1519/20 - c 1585“, in: Contemporaries of Erasmus 1, S. 19.

${ }^{134}$ Anselm Ephorinus wirkte als städtischer Arzt in Krakau. In der Korrespondenz finden sich zwei Schreiben von ihm an Erasmus (vgl. Allen IX, Nr. 2606, 3038). $\mathrm{Zu}$ seiner Biographie vgl. H. Kowalska, s.v. „Anselmus Ephorinus of Freideberg, c 1505 - December 1566“, in: Contemporaries of Erasmus 1, S. 436-437.

135 Vgl. Allen IX, Nr. 2584.

136 Vgl. Allen X, Nr. 2643. Zu seiner Biographie vgl. I. Guenther, s.v. „Johannes Dantiscus of Gdansk, 1 November 1485 - 27 October 1548“, in: Contemporaries of Erasmus 1, S. 377.

137 Vgl. dazu u.a. Allen IX, Nr. 2375, S. 27.74-79. 
Ähnliches ereignen. ${ }^{138}$ Sicher beobachtete man mit Sorge die Entwicklung im Reich und war dankbar für die Informationen, die Erasmus vermittelte, doch ist fraglich, ob trotz aller Aufmerksamkeit eine Ausbreitung reformatorischer Gedanken in Polen im Keim hätte erstickt werden können oder ob nicht eher die ratlose Haltung Benedictis überwog, die erst im Jüngsten Gericht das Ende der Entwicklung befürchtete.

4. Die Jahre von September 1532 bis 1536 : Hoffnung und Enttäuschung

Der letzte, hier zu betrachtende Zeitraum markiert zugleich die letzten dreieinhalb Lebensjahre des Erasmus. Wie der Briefwechsel bezeugt, stand der Rotterdamer unverändert in hohem Ansehen. $\mathrm{Zu}$ seinen, teilweise schon über Jahre hinweg kontaktierten Briefpartnern traten noch drei weitere hinzu: Am 15. Mai 1533 wandte sich ein gewisser Jakob Grofficius an ihn, über den aber nicht mehr bekannt ist, außer dass er Kustos von St. Ägidius in Krakau war. ${ }^{139}$ Am 20. August 1535 sandte Erasmus seinerseits ein Schreiben an Peter Kmita, den Grafen von Wiśnicz. ${ }^{140}$ Nachdem dieser zunächst in der Armee Kaiser Maximilians gedient hatte, war er unter Sigismund I. erst Hof-, 1529 dann Großmarschall von Polen geworden. Erasmus schrieb ihn auf Anraten von Justus Decius an, nachdem der langjährige Patron Szydłowiecki verstorben war. ${ }^{141}$ Sodann wandte sich noch am 16 . August $1536-$ unwissend, dass Erasmus bereits gestorben war - Joseph Tectander auf dem Briefwege an ihn. Auch wenn dies sein erster nachweisbarer Brief ist, kannten sich beide schon länger, da Tectander seinen Schwager Jan Antonin 1524 nach Basel begleitet hatte. ${ }^{142}$ Für Erasmus

${ }^{138}$ Dieser Lesart folgend könnte das Schweigen in den Briefen polnischer Korrespondenten hinsichtlich der reformatorischen Bewegung als gespanntes Warten und aufmerksame Zurkenntnisnahme der Informationen gedeutet werden, die Erasmus regelmäßig vermittelte.

139 Vgl. Allen X, Nr. 2811, S. 228-229, hier: S. 229.61. Vgl. auch H. Kowalska, s.v. "Jakub Groffik of Felsztyn, d after 1538“, in: Contemporaries of Erasmus 2, S. 136.

${ }^{140} \mathrm{Vgl}$. Allen XI, Nr. 3046, S. 211-212, bes. S. 211. Vgl. auch H. Kowalska, s.v. "Piotr Kmita, 1477 - 31 October 1553“, in: Contemporaries of Erasmus 2, S. 264-265.

141 Vgl. Allen XI, Nr. 3046, S. 211.1-10.

${ }^{142}$ Um 1531 studierte Tectander in Padua die freien Künste sowie Medizin. 1532 erwarb er in Krakau den Magistergrad und lehrte auch selbst die Artes, bevor er Sekretär und Leibarzt von Isabella, der Tochter Sigismunds, wurde. Er starb vermutlich um 1542. Vgl. dazu Allen VII, Nr. 1810, S. 29-30, bes. 
waren diese wie überhaupt alle Kontakte nach Polen wertvoll, nach eigener Aussage hatte er hier mehrere Patrone und Freunde. ${ }^{143}$

Im Unterschied zu den vorigen Jahren wurde die reformatorische Entwicklung aber wieder zu dem zentralen Thema der Korrespondenz. Das gilt gleichermaßen für die Briefe von Erasmus wie für die seiner in Polen lebenden Korrespondenten. Die Gründe sind einerseits in den aktuellen Ereignissen zu sehen, die sich zu Beginn der 1530er Jahre in Deutschland und England abspielten, andererseits im Bedürfnis der Korrespondenten, diese Entwicklungen zu diskutieren, sich darüber zu informieren und die Meinung des Gegenübers zu hören. Die Auseinandersetzung mit diesem Thema begann verheißungsvoll, wenn Erasmus gegenüber Piotr Tomicki seiner Hoffnung Ausdruck verlieh, die Glaubenstrennung könne überwunden und zur christlichen Eintracht zurückgekehrt werden. Dies sei sogar rasch möglich, wenn doch nur die Verantwortlichen und das Volk ihren Blick auf Christus richteten, allerdings müsse er gestehen, dass das gegenwärtig selbst bei Bischöfen und Mönchen zu vermissen sei. ${ }^{144}$ Auch ein halbes Jahr später wiederholte Erasmus diese Hoffnung und berichtete davon, dass sich die Lage in Deutschland, vor allem nachdem die Türkengefahr abgewendet worden sei, wieder ausreichend beruhigt habe. Daher hoffe er inständig, dass sich nun auch Kaiser und Papst besprächen, um in kirchlichen Belangen ebenfalls

dort die Anm. zu Tectander, sowie H. Kowalska, s.v. „Josephus Tectander of Cracow, c 1507 - c 1543“, in: Contemporaries of Erasmus 3, S. 313-314.

${ }^{143} \mathrm{Vgl}$. Allen X, Nr. 2776, S. 172-174, hier: S. 172.1-4: „Obiurgat me Iustus Decius, quod nuper, quum ad multos scripsissem quos in Polonia habeo patronos et amicos merito colendos, ad te nihil dederim litterarum, quo non est alius candidior amiciorve Erasmo." Tomicki antwortete auf diesen Brief am 25. August 1533 (vgl. ibidem, Nr. 2861). Einige der erwähnten Freunde nannte Erasmus in einem Brief an Justus Decius vom 1. November 1533 namentlich: Piotr Komicki, Andrzej Krzycki, Johannes Dantiscus, Erasmus, den Abt von Clara Tumba, Jan Łaski, sowie Severin Boner und Johann Antonin (vgl. ibidem, Nr. 2874, S. 309-313, hier: S. 313.189-195). Der nächste Brief des Decius stellt nicht die Antwort auf Nr. 2874 dar, sondern auf einen Brief des Erasmus vom 6. März 1534, der aber verloren ist (vgl. Allen XI, Nr. 2960).

${ }^{144}$ Vgl. Allen X, Nr. 2713, S. 91-92, hier: S. 92.21-22: „Secte hic nunc mitescunt; quid sperent metuantve incertum. Utinam et altera pars sic mitescat ut omnes redeamus ad Christianam concordiam. Id facile fieret si proceres ac populus excusso mundo sinceris animis spectent Christum. Eum affectum hactenus etiam sacerdotibus ac monachis optare licet magis quam cernere." 
wieder zu Frieden zurückzukehren. Allerdings müssten dann auch die Mönche wieder beruhigt werden und die Theologen aufhören, ständig Artikel zu verfassen. ${ }^{145}$ - Aus diesen hoffnungsvollen Situationsberichten darf nicht der Schluss gezogen werden, dass Erasmus die Gefahr im Reich als gebannt ansah. An Johann Łaski gerichtet betonte er, dass eine gewaltsame Unterdrückung schwerwiegende Folgen haben könnte, was ja bereits im Falle der Templer deutlich geworden sei. ${ }^{146}$ Die Situation in England schätzte er aber als bedrohlicher ein: Bereits zweimal hätten die Evangelischen dort zwei sehr gefährliche Aufstände versucht. Nur seinem Freund Thomas Morus sei es zu verdanken, dass niemand auf den Scheiterhaufen gebracht, geköpft oder gehängt worden sei. ${ }^{147}$ In Krakau war die Situation zur gleichen Zeit keineswegs beunruhigend. Es gebe zwar Evangelische, so Johann Łaski, aber erst wenn sie an Zahl zunähmen, könnte eine Gefahr von Tumulten entstehen. Für diesen Fall setzte er aber ganz auf die Autorität des polnischen Königs. ${ }^{148}$ Insofern überwog sowohl in Polen als auch im Reich - zumindest hier nach Einschätzung des Erasmus - die Hoffnung, die Entwicklung in kirchlichen Belangen könne bald einen guten Ausgang nehmen.

Umso überraschter zeigte sich Erasmus, als er davon hörte, Philipp Melanchthon sei von einem nicht näher genannten Bischof nach Polen eingeladen worden. ${ }^{149}$ Dies wollte nicht recht zu dem eindeutig reformationsfeindlichen Eindruck passen, der ihm sonst von polnischer Seite vermittelt wurde. Zwar hielt er Melanchthons Ausdrucksweise für weit weniger aggressiv als die Luthers, in der Lehre hingegen

${ }^{145}$ Vgl. ibidem, Nr. 2776, S. 174.74-80: „Germania sat tranquilla est foeliciter abactis Turcis. Utinam simili foelicitate Caesaris cum Pontifice colloquium Ecclesiam tranquilitati restituat; quae, si quid ego video, maiore in periculo versatur quam plerique credunt. Monachi tumultuantur, theologi scribunt articulos, sed interim genus hominum, non ausim addere quale, cuniculos et radices agunt." - Zeitlich zwischen diesen beiden Schreiben an Tomicki sind noch Briefe einzuordnen, die von Johann Boner (vgl. ibidem, Nr. 2717), Stanislaus Aychler (vgl. ibidem, Nr. 2718), sowie Johann Łaski (vgl. ibidem, Nr. 2746) an Erasmus gerichtet waren.

146 Vgl. ibidem, Nr. 2780, S. 179-181, hier: S. 180.50-181.54: „Omitto nunc Luteri dogmata. Sub hac umbra propagatur ac per orbem di[f]funditur maleficum quoddam errorum genus, quorsum evasurum, Deus novit. Quid tales possint, servile bellum et Templariorum exemplum docet."

147 Vgl. ibidem, Nr. 2780, S. 180.45-49.

148 Vgl. ibidem, Nr. 2862, S. 293-296, hier: S. 295.91-296.97.

149 Vgl. ibidem, Nr. 2911, S. 362-363, hier: S. 363.22-23. 
erschien er ihm gelegentlich lutherischer als Luther selbst. ${ }^{150}$ Leider ist keine Antwort Łaskis auf dieses Schreiben bekannt, aber aus einem früheren Brief an Conrad Goclenius geht hervor, dass Andrzej Krzycki Melanchthon wohl eingeladen habe. ${ }^{151} \mathrm{Im}$ Briefwechsel Melanchthons findet sich darauf jedoch kein Hinweis.

In mehrfacher Hinsicht wandelte sich die zunächst zu beobachtende hoffnungsvolle Stimmung ab dem Sommer 1534 in Enttäuschung - und das sowohl bei Erasmus wie auch durch ihn selbst hervorgerufen: Als er am 22. August 1534 an Justus Decius schrieb, schilderte er ernüchtert die jüngsten Entwicklungen, die ganz Deutschland betrafen. Demnach war in Augsburg allen altgläubigen Predigern ein Predigtverbot auferlegt worden, Messen und Zeremonien waren verboten worden. Nur noch drei Kollegiats- bzw. Klosterkirchen durften Bestand haben, während sich in allen städtischen Kirchen die Evangelischen niederließen. Angesichts dieser Ereignisse ist es nicht überraschend, dass der Ortsbischof geflohen und mit einer Rückkehr nicht zu rechnen war. Die Enttäuschung des Rotterdamers war umso größer, als sich diese Entwicklung nicht auf Augsburg beschränkte. Mit Blick auf die Wiedertäufer bemerkte er, dass sie sich in ganz Niederdeutschland wie die Frösche und Heuschrecken ausbreiteten, deren Plage einst Ägypten heimgesucht habe. ${ }^{152}$ Fast genau ein halbes Jahr später wiederholte Erasmus diese Klagen, als er sich an Piotr Tomicki wandte, wobei er hier noch explizit auf die Ausbreitung der Wiedertäufer in „seinem“ Holland einging. ${ }^{153}$ Angesichts dieser Ereignisse, die sicher auch in Polen erneut

150 Vgl. ibidem, Nr. 2911, S. 363.23-26.

151 Vgl. ibidem, Nr. 2876, S. 314-315, hier: S. 314.23-315.24. Gustav Kawerau hat darauf hingewiesen, dass Dąbrowski im Auftrag Krzyckis Melanchthon eine Einladung nach Polen unterbreitet habe. Bereits 1524 hatte der päpstliche Legat Lorenzo Campeggio mit Hilfe von Friedrich Nausea den Versuch unternommen, Melanchthon von Luther abzuziehen. Diese Hoffnung war nun erneut vor allem durch Melanchthons Auftreten auf dem Augsburger Reichstag 1530 und seine offenkundige Bereitschaft, für den Fortbestand kirchlicher Einheit vieles zu opfern, auf katholischer Seite genährt worden. Vgl. dazu G. Kawerau, Die Versuche, Melanchthon zur katholischen Kirche zurückzuführen (Halle, 1902), S. 6-12.

152 Vgl. Allen XI, Nr. 2961, S. 30-35, hier: S. 33.97-112.

153 Vgl. ibidem, Nr. 3000, S. 78-79, hier: S. 79.45-47: „Iam secta Anabaptistarum dictu mirum quam se late sparserit. Magnam inferioris Germaniae partem occupavit, praecipue meam Holandiam." Tomicki antwortete auf diesen Brief am 26. April 1535 (vgl. ibidem, Nr. 3014). Erasmus wandte sich am 31. August noch einmal an ihn und betonte, dass er nichts Erfreuliches berichten könne - Münster sei 
Sorge aufkommen ließen, war die Hoffnung auf Geschlossenheit in katholischen Reihen groß. Umso größer war daher die Enttäuschung, als Erasmus, den man mittlerweile ebenfalls als entschiedenen Luthergegner ansah, die vom Papst angetragene Kardinalswürde ablehnte. ${ }^{54}$ Piotr Tomicki brachte daher noch ein halbes Jahr vor dem Tod des Rotterdamers in einem langen Brief seine Enttäuschung offen zum Ausdruck, indem er schrieb, Erasmus brauche sich nicht zu wundern, wenn er aufgrund seiner Entscheidung nun von manchen wieder den Lutheranern zugeordnet werde. ${ }^{155}$ - Auch wenn noch vier weitere Briefe zwischen Erasmus und seinen in Polen lebenden Korrespondenten gewechselt wurden, ${ }^{156}$ ist dieser Brief Tomickis das letzte Zeugnis, das die reformatorische Entwicklung zum Thema hat.

Der jahrelange Kontakt des Rotterdamers mit Polen endete daher in doppelter Hinsicht enttäuschend: Einerseits hatten die Entwicklungen im Reich jegliche Hoffnung auf kirchliche Einheit und Beruhigung zunichte gemacht, andererseits war die feste Erwartung der polnischen Korrespondenten, Erasmus würde sich nach langem Zögern unabänderlich zur Papstkirche bekennen, zerstört worden. Dieses ebenfalls enttäuschende Ende der lange währenden Korrespondenz kann jedoch nicht den Eindruck schmälern, dass der von gegenseitiger Wertschätzung, Unterstützung und Freundschaft gekennzeichnete Kontakt für beide Seiten von zentraler Bedeutung war: Die in Polen ansässigen Briefpartner erhielten auf diese Weise nicht nur wertvolle Informationen zu den Ereignissen im Reich aus erster Hand,

mit Gewalt eingenommen worden und die Wiedertäufer breiteten sich von Holland in andere Regionen aus (vgl. ibidem, Nr. 3049, S. 217-222, hier: S. 220.122-129).

${ }^{154}$ Vgl. dazu Galle, op. cit., S. 363; Ribhegge, Erasmus von Rotterdam, S. 207.

155 Vgl. Allen XI, Nr. 3066, S. 240-246, hier: S. 241.21-23, 242.44-53, bes. S. 243.99-100: "Sed tu fortassis hoc metuis, ne in malevolorum, Luteranorum presertim, voculas incurras.“ Vgl. auch ibidem, S. 244.117-125: „Ex quo factum est ut, dum batylla quidem confringenda non censes, sed ignem tantum alienum dispergendum et effundendum, in eam suspicionem nonnullis veneris, te cum Luteranis potius quam cum Ecclesia Romana facere. Quodsi nunc a Summo Pontifice tibi delatum honorem nunc reieceris, confirmabitur ea multorum suspicio. Aut contemni a te amplissimum ordinem et pro nichilo duci putabunt, aut ideo te refugere, ne cum Luteranis in dimicationem descendere cogaris."

${ }^{156}$ Nachweisbar sind noch Briefe an Andrzej Krzycki sowie von Marcin Słap Dąbrowski, Jan Antonin und Joseph Tectander (vgl. ibidem, Nr. 3089, 3121 und 3137-3138). 
sondern auch die gebührende Anerkennung ihrer zahlreichen Humanisten; Erasmus gewann spätestens ab der Mitte der 1520er Jahre in seinen Korrespondenten in Polen die wichtigsten Unterstützer und Patrone, als er in Deutschland, Spanien oder Frankreich zunehmend der Kritik ausgesetzt war.

Insgesamt spiegelt auch die inhaltliche Auswertung den eingangs formulierten Eindruck wider, dass die quantitative Verteilung von Briefen, die Erasmus mit seinen in Polen lebenden Korrespondenten wechselte, auf den Verlauf der reformatorischen Ereignisse zurückzuführen ist. Dennoch ist die Korrespondenz nicht allein von diesem Thema geprägt. So spielen gleichermaßen humanistische Texte eine Rolle und Krakau erhält als ein bedeutendes humanistisches Zentrum in Europa seine verdiente Würdigung. Für Erasmus war der Kontakt nach Polen von ganz persönlicher Bedeutung: Hier fand er in den 1520er und 1530er Jahren genauso ehrenvolle Beachtung und gönnerhafte Patronage, wie sie ihm zuvor von englischen, französischen und deutschen Förderern zuteil geworden war. Deutlich wird dies nicht zuletzt daran, dass er mit den höchsten Vertretern in Staat und Kirche Polens regelmäßig Austausch hatte, von ihnen großzügige Geschenke und ideelle Unterstützung erhielt sowie sich seinerseits durch die Widmung von Texten erkenntlich zeigte.

\section{Bibliographie}

C. Backvis, „La fortune d'Érasme en Pologne“, in: Colloquium Erasmianum. Actes du Colloque International réuni à Mons du 26 au 29 octobre 1967 à l'occasion du cinquième centenaire de la naissance d'Érasme (Mons: Mons Centre Universitaire de l'État, 1968), S. 173-202

Erasmus-Rezeption im 16. Jahrhundert, hrsg. v. C. Galle, T. Sarx (Frankfurt a. M. et al.: Verlag Peter Lang, 2012; Kulturgeschichtliche Beiträge zum Mittelalter und zur frühen Neuzeit, 5)

C. Galle, Hodie nullus - cras maximus. Berühmtwerden und Berühmtsein im frühen 16. Jahrhundert am Beispiel des Erasmus von Rotterdam (Münster: Aschendorff Verlag, 2013; Reformationsgeschichtliche Studien und Texte, 158 [Phil. Diss.])

J. Glomski, „Erasmus and Cracow (1510-1530)“, Erasmus Studies 17 (1997), S. $1-18$

H. Louthan, „A Model for Christendom? Erasmus, Poland and the Reformation", Church History 83 (2014), S. 18-37 
Polnisch-deutsche Wechselbeziehungen im zweiten Millennium, Tl. 1: Zur polnisch-deutschen Kulturkommunikation in der Geschichte - Materialien, hrsg. v. J. Papiór (Bydgoszcz: Wydawnictwo Akademii Bydgoskiej, 2001)

W. Ribhegge, Erasmus von Rotterdam (Darmstadt: Wissenschaftliche Buchgesellschaft, 2010)

\section{Bishops, Humanists and Simple Luther's Enemies. Erasmus' Contacts with Poland Seen Through his Correspondence}

Letters have been the most important communication medium for fifteenthand sixteenth-century humanists. The correspondence of Erasmus of Rotterdam has already been considered to be one of the most famous collection of letters relative to its contemporaries. One reason was that probably no one else stayed in contact with the intellectual, secular, and ecclesiastical elites of so many European countries. It is also a valuable source to identify Erasmus' Polish or living in Poland correspondents and to present them prosopographically in short biographies. Their letters let one also receive an impression, of how the reformation in Germany was received and criticized in the neighboring country, the Polish kingdom. During the years from 1518 to 1536 different feelings mark the discussions in Poland, which ranged from a disturbed and distant observation over the painful search for suitable instruments to prevent a spreading of the reformation into the Polish kingdom, to lastly hope for the ones, and resignation for the others. Thereby, the reception of the reformation from abroad can be illustrated, and different views among Erasmus' Polish correspondents become understandable.

Christoph Galle, dr, po obronie doktoratu zatrudniony jako Akademischer Rat na Wydziale Historii Kościoła Uniwersytetu w Marburgu (Niemcy). Po studiach na kierunkach filologia klasyczna (latynistyka) i historia starożytna, jak też historia średniowieczna i nowożytna oraz nowoczesna brał udział w dwóch projektach badawczych: „Wczesne listy Marcina Lutra” oraz „Łacińska Biblia Marcina Lutra”, a także napisał doktorat na temat kariery Erazma z Rotterdamu. Rozprawa habilitacyjna, nad którą obecnie pracuje, dotyczy wczesnośredniowiecznych zbiorów kazań, w szczególności karolińskich. Z związku z tym był gościem Bibliotheca Fuldensis (Fulda, Niemcy) oraz Wydziału Teologii Uniwersytetu w Oksfordzie i Instytutu Studiów Zaawansowanych Uniwersytetu w Durham (Wielka Brytania).

Christoph Galle $\mathrm{PhD}$ is working as an Akademischer Rat (= postdoc position) in the Department of Church History at Marburg University, Germany. After having studied Classical Philology (Latin) and History as well 
as Medieval and Early Modern Latin and Modern History he took part in two research projects on "Martin Luther's early letters" and "Martin Luther's Latin Bible", and wrote a dissertation on the career of Erasmus of Rotterdam. His Habilitationsschrift (= habilitation dissertation), on which he is working, deals with early medieval, especially Carolingian sermon collections. In this regard, he was visiting scholar at the 'Bibliotheca Fuldensis' (Fulda, Germany), the Faculty of Theology (University of Oxford, UK), and at the Institute of Advanced Studies (Durham University, UK).

E-mail: gallec@uni-marburg.de 